\title{
Chitinase 3-like-1 is a Therapeutic Target That Mediates the Effects of Aging in COVID-19
}

\author{
Suchitra Kamle ${ }^{1}$, Bing $\mathrm{Ma}^{1}$, Chuan Hua He${ }^{1}$, Bedia Akosman ${ }^{1}$, Yang Zhou ${ }^{1}$, \\ Chang Min Lee ${ }^{1}$, Wafik S. El-Deiry ${ }^{2-5}$, Kelsey Huntington ${ }^{2-5}$, Olin Liang ${ }^{3,4,5}$, Jason T. Machan ${ }^{6}$, \\ Min-Jong Kang ${ }^{7}$, Hyeon Jun Shin ${ }^{7}$, Emiko Mizoguchi ${ }^{1,8}$, Chun Geun Lee ${ }^{1}$ and Jack A.

$$
\text { Elias }^{1,4,5,9,10}
$$

${ }^{1}$ Molecular Microbiology and Immunology

Brown University

185 Meeting St.

Providence, RI. 02912, USA

${ }^{2}$ Pathology and Laboratory Medicine

Brown University

Ship Street Research Building

Providence RI 02906 USA

${ }^{3}$ Hematology-Oncology Division,

Department of Medicine, Lifespan Health System

Warren Alpert Medical School, Brown University, Providence, RI, 02912

${ }^{4}$ The Joint Program in Cancer Biology,

Brown University and Lifespan Health System, Providence, RI, 02912

${ }^{5}$ Cancer Center at Brown University,

Warren Alpert Medical School, Brown University, Providence, RI, 02912

${ }^{6}$ Department of Biostatistics

Lifespan Health System

Providence, RI 02906

${ }^{7}$ Section of Pulmonary, Critical Care and Sleep Medicine

Department of Internal Medicine, Yale University School of Medicine

New Haven, CT 06510

${ }^{8}$ Department of Immunology

Kurume University, School of Medicine

Kurume, Fukuoka 830-0011, Japan

\author{
${ }^{9}$ Department of Medicine \\ Brown University \\ Providence, RI 02912, USA \\ ${ }^{10}$ corresponding author: jack_elias@brown.edu
}

Running Title: A CHI3L1 Therapeutic Platform in COVID-19 


\begin{abstract}
COVID-19 is caused by the SARS-CoV-2 (SC2) virus and is more prevalent and severe in the elderly and patients with comorbid diseases (CM). Because chitinase 3-like-1 (CHI3L1) is induced during aging and $\mathrm{CM}$, the relationships between $\mathrm{CHI} 3 \mathrm{~L} 1$ and SC2 were investigated. Here we demonstrate that $\mathrm{CHI} 3 \mathrm{~L} 1$ is a potent stimulator of the SC2 receptor ACE2 and viral spike protein priming proteases (SPP), that ACE2 and SPP are induced during aging and that anti-CHI3L1, kasugamycin and inhibitors of phosphorylation, abrogate these ACE2- and SPP-inductive events. Human studies also demonstrated that the levels of circulating CHI3L1 are increased in the elderly and patients with CM where they correlate with COVID-19 severity. These studies demonstrate that $\mathrm{CHI} 3 \mathrm{~L} 1$ is a potent stimulator of ACE2 and SPP; that this induction is a major mechanism contributing to the effects of aging during SC2 infection and that $\mathrm{CHI} 3 \mathrm{~L} 1$ coopts the $\mathrm{CHI} 3 \mathrm{~L} 1$ axis to augment SC2 infection. CHI3L1 plays a critical role in the pathogenesis of and is an attractive therapeutic target in COVID-19.
\end{abstract}




\section{Introduction}

SARS-CoV-2 (SC2) is a novel coronavirus that was initially appreciated in man in 2019. It is highly transmissible and has caused a global pandemic killing $>1.5$ million people and infecting > 80 million people worldwide as of December, 2020 (1-7). The disease caused by SC2, COVID-19, was initially noted to manifest as a pneumonia with fever, cough, fatigue and dyspnea as major manifestations (8). However, it is now known to be a systemic disease with manifestations in many organs $(9,10)$. In addition, it is now known that there is a spectrum of disease severity with patients that are asymptomatic, $10-20 \%$ of patients that require hospitalization $(4,5,11)$. and patient with respiratory failure that require intensive care $(12)$. Unique clinical features have also been described including pulmonary fibrosis, an increased frequency of vascular thrombotic events, a coagulopathy and pulmonary angiitis (13, 14). However, the cellular and molecular events that account for this impressive clinical and pathologic heterogeneity are poorly understood.

One of the most unique features of COVID-19 is its impressive relationship to aging and comorbid disorders. The elderly is at increased risk of contracting COVID-19 and experience higher complication and case fatality rates $(15,16)$. COVID-19 has also been devastating effects on and elderly and residents of congregate care facilities $(17,18)$. Similarly, approximately $50 \%$ of hospitalized COVID-19 patients have preexisting medical conditions including diabetes, hypertension, obesity and metabolic syndrome, cardiovascular disease and chronic lung diseases like COPD and asthma. These co-morbidities associate with enhanced susceptibility to SC2 infection, more severe disease and a higher mortality $(1-3,5,15,19,20)$. Surprisingly, the cellular and molecular events that underlie the effects of aging and comorbid diseases in COVID-19 have not been defined.

SC2 interacts with cells via its spike (S) protein which binds to its host cell receptor angiotensin converting enzyme 2 (ACE2) which mediates viral entry (21-24). After binding, the S 
protein is processed by the S priming proteases (SPP) TMPRSS2, Cathepsin L (CTSL) and in some cases FURIN into S1 and S2 subunits. The latter mediates the fusion of the viral envelope and cell plasma membrane which is required for virus-cell entry $(15,19,23)$. In the human disease, SC2 passes through the mucus membranes of the upper and lower respiratory tracts and infects epithelial cells via this ACE2-S protein-protease mechanism $(15,19,25)$. The virus can then enter the bloodstream and, via this viremia, infect other cells and organs that express ACE2 and SPP (26). It has been proposed that the levels of expression of ACE2 and the SPP play key roles in determining the magnitude and organ location of the infection and the severity of the disease $(15,19,27)$. However, the mechanisms that SC2 uses to generate its effects in different tissues have not been defined. Furthermore, although ACE2 is expressed widely in human tissues (15), the critical processes that regulate ACE2 expression and activation have only recently begun to be investigated.

Virus infection of mammalian cells leads to innate and adaptive immune responses that restrict viral replication, augment viral clearance and limit tissue damage and disease severity (28). To allow infection to occur many viruses have developed strategies to evade and or suppress these immune responses (28-30). They can also co-opt host responses to augment viral replication (28-30). These events can drastically influence disease pathogenesis, the course of the infection, disease severity and viral persistence in the host (28-30). Compared to other positive stranded (+) RNA viruses, coronaviruses have exceptionally large genomes and employ complex genome expression strategies (28). Many of the coronavirus genes participate in virushost interplay to create an optimal environment for viral replication (28). However, the host pathways that SC2 co-opts to foster infection and replication have not been adequately defined and the possibility that SC2 utilization of host responses contributes to the mechanisms by which aging and comorbid diseases augment the prevalence and severity of COVID-19 has not been addressed. 
Chitinase 3-like-1 (CHI3L1; also called YKL-40 in human and Chil1 or BRP-39 in mouse) is an evolutionarily conserved member of the 18 glycosyl hydrolase $(\mathrm{GH} 18)$ gene family that is produced by a spectrum of cells in response to a variety of injury and cytokine stimuli (31-35). It is the cornerstone of a critical pathway that is activated during injury and inflammation, regulates innate and adaptive immunity and heals and protects $(32,34,36-38)$. The latter is mediated by its ability to inhibit apoptosis and other forms of cell death while driving fibroproliferative repair $(36,38)$. CHI3L1 is readily detected in the circulation of normals and the levels of circulating and tissue $\mathrm{CHI}$ L1 are increased in diseases characterized by inflammation, injury, remodeling and repair $(31-33,37,39-46)$. Interestingly $\mathrm{CHI} 3 \mathrm{~L} 1$ is also expressed in an exaggerated manner in aging and in the same comorbid diseases that are risk factors for COVID-19 (47-54). CHI3L1 and ACE2 are also both mediators of pulmonary protective responses $(36,55-58)$. In light of these impressive similarities we hypothesized that the induction of ACE2 and SPP is part of the CHI3L1induced healing and repair response. We also hypothesized that SC2 co-opts the host CHI3L1 axis to augment its ability to infect, spread and generate disease. To address these hypotheses, we used genetically modified mice, in vitro approaches and human cohorts. These studies demonstrated that (a) CHI3L1 is a potent stimulator of ACE2 and SPP in pulmonary epithelial cells and vascular cells; (b) that the expression of ACE2 and SPP are increased during murine aging and that these aging-induced inductive events are mediated by CHI3L1; and (c) that interventions that alter $\mathrm{CHI} 3 \mathrm{~L} 1$ effector responses are also potent inhibitors of ACE2 and SPP and viral infection. Lastly, human studies demonstrated that the levels of circulating CHI3L1 are increased in COVID-19 (+) patients that are elderly, have comorbid diseases and manifest severe COVID-19 disease. These findings support the concept that CHI3L1 plays a critical role in the pathogenesis of and is an attractive therapeutic target in COVID-19. They also provide a mechanistic explanation for how aging and comorbid diseases contribute to the pathogenesis of COVID-19. 


\section{Results}

\section{CHI3L1 regulation of pulmonary ACE2 and SPP in vivo}

To begin to address the relationship(s) between $\mathrm{CHI} 3 \mathrm{~L} 1$ and SC2, we characterized the effects of CHI3L1 on the expression and accumulation of ACE2 and SPP in vivo. In these studies, we compared the expression of Ace 2 and SPP in lungs from inducible CC10 promoter-driven CHI3L1 overexpressing Tg mice (CHI3L1 Tg) and wild type (WT) controls. These studies revealed the induction of Ace2, Tmprss2 and Ctsl in lungs from CHI3L1 Tg mice (Fig. 1, A and B). Ace2 protein was most prominent in airway epithelium where it colocalized with CC10 (Fig. 1C and Supplemental Fig. S1). Ace2 was also seen in alveoli where it co-localized with pro-SP-C (Fig. 1C and Supplemental Fig. S1). Tmprss2 and Ctsl were also prominently expressed in airway epithelial cells (Fig. 1, C and D and Fig. S1) and TMPRSS2 was also seen in alveolar macrophages (Fig. 1D).

$\mathrm{Tg} \mathrm{CHI}$ L1 also augmented the expression and accumulation of Ace2 and SPP in pulmonary blood vessels. Immunohistochemistry demonstrated that Ace2 and Tmprss2 colocalized with CD-31 on endothelial cells and transgelin (+) vascular smooth muscle cells (Fig. 1E and Supplemental Fig. S1). When viewed in combination these studies demonstrate that CHI3L1 is a potent stimulator of epithelial and vascular cell ACE2 and SPP in vivo.

\section{CHI3L1 regulation of pulmonary ACE2 and SPP in vitro}

In vitro experiments were next undertaken to determine if $\mathrm{rCH} 3 \mathrm{~L} 1$ regulated the expression and or accumulation of ACE2 and SPP. These studies demonstrated that rCHI3L1 stimulated ACE2 and SPP (TMPRSS2, Cathepsin L) gene expression and protein accumulation in human Calu-3 epithelial cells in a time- and dose-dependent manner (Fig. 2, A and B). These effects were not Calu-3 cell specific because similar results were obtained with A549 epithelial cells, primary human small airway epithelial cells (HSAEC cells) and lung fibroblasts 
(Supplemental Figs. S2 and S3). When viewed in combination, these studies demonstrate that CHI3L1 stimulates ACE2 and SPP in a variety of cells in vitro.

\section{Consequences of ACE2 and SPP induction}

To understand the consequences of CHI3L1 induction of ACE2 and SPP, studies were undertaken to determine if this induction augmented the ACE2 receptor binding of Spike (S) protein and or the metabolism of S into its S1 and S2 subunits. In these experiments lysates were prepared from Calu-3 cells incubated with rCHI3L1 or vehicle control and recombinant (r) spike protein was added. To assess S-receptor binding, immunoprecipitation and immunoblots were serially undertaken with anti-ACE2 and anti-S respectively. To assess $S$ metabolism, the cell lysates were incubated for 24 hours with rS and Western blots were undertaken with S1 and S2 specific antibodies. As can be seen in Figs. 2C and 2D, CHI3L1 stimulation was associated with enhanced ACE2-S binding and enhanced metabolism of $S$ into its respective subunits.

To further address the consequences of these inductive events, Pseudovirus moieties were generated by incorporating the SC2 "S" protein into lentivirus moieties which contained a GFP marker. The infectious capacity of these pseudovirus $S$ moieties was then evaluated using cells incubated with $\mathrm{rCHI} 3 \mathrm{~L} 1$ or control vehicle. In keeping with the findings noted above, rCHI3L1 induction of ACE2 and SPP augmented pseudovirus S incorporation into lung epithelial cells. (Fig. 2E). FACS evaluations further confirmed these observations by demonstrating that rCHI3L1 enhanced the cellular integration of S-protein containing pseudovirus and that treatment with antiCHI3L1 monoclonal antibody (FRG) ameliorated rCHI3L1-stimulated pseudovirus cell integration (Fig. 2F). CHI3L1 similarly enhanced the cellular integration of pseudovirus containing $S$ sequence with D416 or G416 and FRG treatment inhibited pseudoviral infection regardless of S sequence (Fig. 2F). When viewed in combination, these studies demonstrate that CHI3L1 stimulation of ACE2 and SPP increases S-ACE2 binding, $S$ metabolism and pseudovirus $S$ infection. 


\section{Monoclonal and small molecule CHI3L1-based therapeutics}

The finding that $\mathrm{CHI} 3 \mathrm{~L} 1$ is a potent stimulator of ACE2 and SPP raises the interesting possibility that CHI3L1 may be a useful therapeutic target in COVID-19. To begin to address this possibility, we characterized the effects of a humanized monoclonal antibody against CHI3L1 developed in our laboratory (called FRG), and a small molecule Chitinase 1 and CHI3L1 inhibitor called kasugamycin in vitro and in vivo. The monoclonal inhibitor of CHI3L1 (FRG) was a potent inhibitor of CHI3L1 stimulation of epithelial cell ACE2 and SPP in vitro (Fig. 3, A and B). FRG was also a powerful inhibitor of Tg CHI3L1 induction of ACE2 and SPP in vivo (Fig. 3C). Interestingly, kasugamycin was a similarly powerful inhibitor of CHI3L1 induction of ACE2 and SPP in vitro and in vivo (Fig. 3, D\&E). These studies highlight antibody-based and small molecule CHI3L1 inhibitors that control ACE2 and SPP and have promise as therapeutics in COVID-19.

\section{CHI3L1 phosphorylation-based therapeutics}

To date, all studies of CHI3L1 have assumed that it is not post-translationally modified. However, phosphorylation site prediction analysis using the NetPhos program (v2.0) suggests that $\mathrm{CHI} 3 \mathrm{~L} 1$ is a phosphoprotein with high potential for serine/threonine phosphorylation. Further investigation also provided a number of lines of evidence that suggest that $\mathrm{CHI} 3 \mathrm{~L} 1$ is effective as a phosphoprotein. This included (a) sequence mining of $\mathrm{CHI} 3 \mathrm{~L} 1$ which revealed a cyclin binding domain that is highly predictive of CDK phosphorylation (Supplemental Fig. S4); (b) sites of serine phosphorylation of $\mathrm{rCHI} 3 \mathrm{~L} 1$ confirmed with immunoblot assays with an anti-phosphoserine antibody (EMD Millipore, AB1603) (Fig. 4A); (c) the demonstration that CHI3L1 phosphorylation is dependent on CDK activity based on its inhibition by the broad spectrum CDK inhibitor Flavopiridol. As a result we hypothesized that phosphorylation in this region is essential for CHI3L1 effector responses. To address this hypothesis we used in vitro and in vivo approaches. In the former, we generated $\mathrm{WT} \mathrm{CHI} 3 \mathrm{~L} 1$ and mutant forms of $\mathrm{rCHI} 3 \mathrm{~L} 1$ that could not be 
phosphorylated and compared their ability to induce epithelial cell ACE2 and SPP. As can be seen in Fig. 4B, WT CHI3L1 was a powerful stimulator of epithelial ACE2 and SPP and this effect was abrogated by mutations at AA 230 (Serine to Arginine mutation at site of amino acid 230 of CHI3L1). Mutations at AA 235 or 237 did not have similar effects (data not shown). In the in vivo experiments, we compared the effects of transgenic $\mathrm{CHI} 3 \mathrm{~L} 1$ in mice treated with the broad spectrum CDK inhibitor Flavopiridol (Fig. 4C) or the selective CDK 1 and 2 inhibitor (BMS 265246) and their vehicle controls (Fig. 4D). In both cases, the CDK inhibitors abrogated the ability of CHI3L1 to stimulate epithelial cells ACE2 and SPP. These studies demonstrate that CHI3L1 is effective as a phosphoprotein and highlight the ability of CDK inhibitors, particularly inhibitors of CDK 1 and 2, to control this phosphorylation and, in turn, serve as a therapeutic in COVID-19.

\section{CHI3L1 and Aging in COVID-19}

The elderly is at increased risk of contracting COVID-19 and experience higher complication and case fatality rates $(15,16)$. These unique features have interesting parallels in the CHI3L1 axis where the levels of circulating CHI3L1 increase with aging (59). To further understand these relationships, we measured the levels of circulating CHI3L1 in WT mice as they age. As can be seen in figure $5 \mathrm{~A}$, the levels of circulating $\mathrm{CHI} 3 \mathrm{~L} 1$ and the levels of downstream ACE2, and SPP increased significantly in comparisons of 6 and 12-month-old WT mice. Importantly, treatment of WT mice twice a week with the monoclonal antibody FRG from 6 months to 12 months of age was remarkably effective in inhibiting the expression and accumulation of CHI3L1, ACE2 and SPP in aged mice (Fig. 5B). These studies demonstrate that the increase in circulating $\mathrm{CHI} 3 \mathrm{~L} 1$ that is seen with aging stimulates the expression and accumulation of ACE2 and SPP. They also suggest that these changes in CHI3L1, ACE2 and SPP contribute to the pathogenesis of the heightened COVID-19 responses in the elderly.

\section{Circulating CHI3L1 in COVID-19}


As noted above, SC2 infections are more common and more severe in the elderly and patients with comorbid diseases $(1-3,5,15,19,20)$. Studies from our laboratory and others have also demonstrated that the levels of circulating $\mathrm{CHI} 3 \mathrm{~L} 1$ are also increased in the diseases that are COVID-19 risk factors (47-54). Thus, to further understand the relationships between CHI3L1 and the COVID-19 risk factors, we measured the levels of CHI3L1 in the serum of normal healthy individuals and patients presenting to the emergency department (ED) at Rhode Island Hospital for medical evaluations that prompted a COVID-19 diagnostic evaluation. The demographics of these cohorts can be seen in supplemental Table S1. In keeping with reports from our laboratory and others the majority of the normal healthy individuals had levels of circulating CHI3L1 between 15 and $60 \mathrm{ng} / \mathrm{ml}$ (Fig. 6A). Interestingly, the levels of circulating CHI3L1 in the individuals in the normal healthy cohort was not significantly different than the levels in patients presenting to the ED who did not have comorbid diseases (hypertension, diabetes, arthritis, neurologic disease, cancer, stroke, obesity and or chronic lung disease) (Fig. 6A). They were however, significantly lower than the levels in the circulation of patients presenting to the ED with existing comorbid diseases (Fig. 6A) and patients that tested positive for COVID-19 (Fig. 6B). When the COVID-19 $(-)$ and (+) ED patients were evaluated together the levels of circulating CHI3L1 were increased in the patients that were greater than 50 years of age (Fig. 6C) and or had hypertension (Fig. 6D). The levels of circulating CHI3L1 correlated with COVID-19 disease severity. This can be seen in Figures $6 \mathrm{E}$ and $6 \mathrm{~F}$ which demonstrate that the levels were significantly increased in patients that were admitted to the hospital compared those that were discharged to home (Fig. 6E) and that the circulating levels of CHI3L1 were significantly increased in patients with higher COVID Severity Scores (CSS) (Fig. 6F and Table S2). When only COVID-19 (+) patients were evaluated, the levels of circulating $\mathrm{CHI} 3 \mathrm{~L} 1$ were increased in patients with hypertension versus those without hypertension; patients that were admitted versus those that were sent home from the ED; patients that were greater than 50 years old versus younger individuals and patients with comorbid diseases versus COVID-19 (+) patients without concurrent comorbid disorders (Fig. 6, G-J). 
Overall, these studies demonstrate that the levels of circulating $\mathrm{CHI} 3 \mathrm{~L} 1$ are increased in the elderly and patients with comorbid disease like hypertension. They also demonstrate that the levels of circulating CHI3L1 are increased in COVID-19 (+) patients that are elderly, have comorbid diseases and manifest severe COVID-19. These observations support the concept that SC2 co-opts the CHI3L1 axis to stimulate ACE2 and SPP which augment viral infection and foster SC2 disease manifestations. They also suggest that the effects of the COVID-19 risk factors are mediated, at least in part, by their ability to stimulate $\mathrm{CHI} 3 \mathrm{~L} 1$.

\section{Discussion}

The $\mathrm{CHI} 3 \mathrm{~L} 1$ axis is a major endogenous healing and repair response and ACE2 is a protective moiety in acute lung injury $(A L I)(38,55-57)$. To determine if they are related to one another, we characterized the effects of CHI3L1 on ACE2 and SPP in vivo and in vitro. In our initial studies, we compared the expression of Ace2 and SPP in lungs from CC10-driven CHI3L1 overexpressing Tg mice and WT controls. These studies demonstrated induction of Ace2, Tmprss2 and CtsL in lungs from $\operatorname{Tg}(+)$ mice. Ace2 was most prominent in airway epithelium. It was also seen in alveoli where it co-localized with SP-C and CC10 and stained blood vessels where it co-localized on endothelial and smooth muscle cells. Tmprss2 and Ctsl were also seen in airway epithelial cells and Tmprss 2 was seen in alveolar macrophages. In the in vitro experiments $\mathrm{rCHI} 3 \mathrm{~L} 1$ impressively stimulated the levels of mRNA encoding ACE2, TMPRSS2 and CTSL in human lung epithelial cell lines (Calu-3, A549) and primary human small airway epithelial cells (HSAEC) and lung fibroblasts. Importantly, these inductive responses were markedly decreased by treatment with moieties that alter $\mathrm{CHI} 3 \mathrm{~L} 1$-induced effector responses such as monoclonal anti-CHI3L1 (FRG), kasugamycin and inhibitors of CHI3L1 phosphorylation. These findings support the concept that SC2 co-opts the CHI3L1 healing and repair response to increase the number of cellular targets for viral entry. They also suggest that the host's attempt 
to heal and repair via CHI3L1 is complicit in SC2 viral infection and COVID-19 morbidity and mortality.

In the time since the outbreak of the COVID-19 pandemic unique features of its epidemiology have been appreciated. This includes the impressive increase in the prevalence and severity of the disease in the elderly, particularly those in congregate care settings $(16,17)$. The prevalence and severity of COVID-19 are also increased in patients with comorbid diseases including diabetes, hypertension, obesity and metabolic syndrome, cardiovascular disease and chronic lung diseases like COPD where they associate with enhanced susceptibility to SC2 infection, more severe disease and a higher mortality $(1-3,5,15,19,20)$. These unique features have interesting parallels in CHI3L1. Specifically, the levels of circulating CHI3L1 increase with aging. In fact, they have been reported to be the best predictor of all-cause mortality in octogenarians (59). In addition, studies from our laboratory and others have demonstrated that the levels of circulating $\mathrm{CHI} 3 \mathrm{~L} 1$ are also increased in the very diseases that are COVID-19 risk factors (47-54) where they correlate with disease severity $(49,50,53)$. ACE2 expression and viral loads have been suggested to increase with aging and it has been proposed that these changes can explain the impressive severity of COVID-19 in the elderly and patients with comorbid diseases $(16,17)$. Our studies support this contention and provide novel insights into the mechanisms that may underlie these associations by demonstrating that the levels of circulating $\mathrm{CHI} 3 \mathrm{~L} 1$ increase during murine aging, that these inductive events are abrogated by treatment with anti-CHI3L1 and that CHI3L1 stimulates ACE2 and SPP which increases ACE2-S protein-cell interaction, S protein activation and pseudovirus-S infection.

COVID-19-associated vasculitis and vasculopathy are now considered defining features of the systemic disease caused by SC2 $(10,60)$. The importance of vascular alterations can also be appreciated in recent studies comparing the lungs of patients infected with SC2 and influenza (13). Both manifest diffuse alveolar damage and perivascular infiltrating lymphocytes. There were, however, distinctive vascular manifestations in the COVID-19 tissues. They included (a) 
severe endothelial injury with intra-endothelial SC2 virus and disrupted endothelial membranes; (b) widespread vascular thrombosis; and (c) elevated levels of intussusceptive angiogenesis. They also noted increased numbers of ACE2+ endothelial cells in infected patients versus controls (13). These and other studies have led to the belief that endothelial injury plays a key role in these responses and that the injury is caused by direct viral infection and perivascular inflammation $(10,13)$. Our studies support this concept by demonstrating, for the first time, that CHI3L1 is a powerful stimulator of endothelial cell and vascular smooth muscle cell ACE2 and SPP. They also raise the intriguing possibility that the $\mathrm{CHI} 3 \mathrm{~L} 1$ is a key stimulator of the pulmonary and systemic manifestations of COVID-19 and that it does this, at least in part, by enhancing the susceptibility of endothelial cells and smooth muscle cells to infection with the virus.

Studies from our lab and others have demonstrated that $\mathrm{CHI} 3 \mathrm{~L} 1$ is a critical regulator of inflammation and innate immunity and a stimulator of Type 2 immune responses, fibroproliferative repair and angiogenesis $(34,37,38,61-65)$. These studies also demonstrated that CHI3L1 is dysregulated in a variety of diseases characterized by injury, inflammation and or tissue remodeling (31-33, 37, 39-46). In keeping with these findings, we focused our recent efforts on the development of CHI3L1-based interventions that could serve as therapeutics for CHI3L1dependent diseases. These studies have defined an exciting therapeutic platform based on CHI3L1. Our initial studies focused on biologic approaches and the generation of a panel of monoclonal antibodies against CHI3L1 using full length and peptide immunogens. These antibodies were assessed in a variety of murine models. The most impressive responses were obtained with a monoclonal antibody against a peptide that contained the sequence between AA 223-234 of human CHI3L1. This antibody is now called FRG. It was originally a mouse IgG2b kappa. A humanized version has been generated on an IgG1 backbone. There are a number of reasons to believe that FRG can be an effective therapeutic in COVID-19. First, FRG is a potent inhibitor of the basal levels and the CHI3L1-stimulated expression and accumulation of ACE2 and SPP. It is also important to point out that studies from our lab and others have demonstrated that 
CHI3L1 drives inflammation in a type 2 direction and augments type 2 and decreases type $1 \mathrm{~T}$ cell differentiation $(34,66)$. This is problematic for COVID-19 because, in contrast to type 2 immunity, type1 immune responses have potent antiviral effects (67). Thus, FRG treatment would abrogate CHI3L1 stimulation of type 2 responses and augment type 1 antiviral responses in a number of cells and tissues. FRG also inhibits fibroproliferative repair which could ameliorate the pathologic fibrosis that occurs in patients with respiratory failure due to COVID-19 who are intubated for an extended interval (68). Based on these observations one can see how FRG could be used as a prophylactic to diminish the chances of an individual getting infected after exposure to a SC2-infected person. One can also see how FRG, alone or in combination with antivirals such as remdisivir, could be therapeutically useful in patients with established SC2 infection.

Kasugamycin was isolated from Streptomyces kasugaensis in 1965 (69). It was initially appreciated to inhibit the growth of fungi, later noted to have modest antibacterial properties and most recently shown to inhibit influenza and other viral infections (70). This prompted us to undertake experiments designed to determine if Kasugamycin altered the effects of CHI3L1. These studies demonstrated that Kasugamycin is a powerful inhibitor of CHI3L1 induction of epithelial ACE2 and SPP. Other studies also demonstrated that kasugamycin inhibits type 2 immune responses and pathologic fibrosis (Elias JA, Lee, CG unpublished observation). The ability of Kasugamycin to ameliorate CHI3L1 induction of ACE2 and SPP while exerting antiviral and antifibrotic effects and augmenting Type I immune responses suggests that it is a useful agent that can be used as a prophylactic or therapeutic in COVID-19. This is an interesting prospect because Kasugmycin has been used as an antibiotic in man with minimal complications (71) and in agricultural settings where EPA evaluation has demonstrated an impressive lack of toxicity (72).

Our studies demonstrate that $\mathrm{CHI} 3 \mathrm{~L} 1$ has an activated state that is phosphorylated and that this activation is mediated by CDKs. They also demonstrate that AA 230 plays a critical role in $\mathrm{CHI} 3 \mathrm{~L} 1$ effector responses. In keeping with these findings Flavopiridol, a broad spectrum CDK 
inhibitor, proved to be a powerful inhibitor of CHI3L1 stimulation of ACE2 and SPP in vitro and in vivo. This is likely due, in great extent, to the inhibition of CDK 1 and or 2 because BMS 265246 had similar effects. It is also tempting to speculate that, because the monoclonal antibody FRG was generated against a site of phosphorylation, that its impressive potency is the result of its ability to function as a blocking antibody and its ability to interfere with this critical phosphorylation site. These findings suggest that Flavopiridol, BMS265246 and possibly other CDK inhibitors could be useful therapeutics in COVID-19. This could be an exciting example of drug repurposing because Flavopiridol, which is also called Alvocidib, has already received orphan drug designation from the FDA and EMA for the treatment of CLL (73).

RNA viruses often trigger the RIG like helicase (RLH) innate immune system. In this response, antiviral immunity is triggered by the dsRNA and 5' triphosphate bearing molecules that arise in the cytosol as viral replication intermediates. These moieties are recognized by widely expressed cytoplasmic sensors from the RIG-I-like receptor family including retinoic acidinducible gene I (RIG-I) and melanoma differentiation-associated protein 5 (mda-5) (28). The RIG-I receptor with its attached replication intermediate then interacts with mitochondrial MAVS (mitochondrial antiviral signaling molecule), the central integrator of this pathway, to triggers a type I interferon (IFN)-based antiviral response (28). The RLH pathway plays a major role in viral control and clearance. Interestingly, studies from our laboratory have also demonstrated that the RLH pathway is also a powerful inhibitor of $\mathrm{CHI} 3 \mathrm{~L} 1$ expression and accumulation (74). Based on these observations one would expect that SC2 infection and subsequent RLH activation would decrease the levels of circulating $\mathrm{CHI} 3 \mathrm{~L} 1$. This would decrease the expression of ACE2 and SPP which would decrease viral infection and spread and subsequent tissue injury. In keeping with the appreciation that viruses have evolved strategies that suppress or evade antiviral immunity (75), the levels of induction of type I IFNs are decreased in patients with COVID-19 $(76,77)$. We believe this decreased production of type I IFNs is a major contributor to the prevalence and 
severity of COVID-19 because it would increase the levels of circulating Chi3I, increase the expression and accumulation of ACE2 and SPP and augment viral infection and spread.

Early strains of SARS-CoV-2 from Wuhan China showed limited genetic diversity (78). However, genetic epidemiologic investigations conducted in late February 2020 have identified an emerging D614G mutation of the SARS-CoV-2 spike protein in viral strains from Europe (78, 79). Patients infected with D614G associated SARS-C0V-2 manifest enhanced viral loads. Pseudotyped virus with G614 mutations also manifest enhanced viral infectivity based on a spike protein that is more likely to assume an "open" configuration and bind to ACE2 with enhanced avidity (78). One can envision how S protein mutations can lead to viruses that are increasingly problematic from a therapeutic perspective. However, one can also see how CHI3L1-based therapeutics which inhibit ACE2 and SPP can inhibit SARS-CoV-2 infection regardless of the S protein sequence.

Our studies demonstrate that CHI3L1 is a major stimulator of ACE2 and SPP that enhances SC2 "S" protein-receptor binding and activation and augments SC2 infection and spread. They also led us to appreciate that the levels of circulating $\mathrm{CHI} 3 \mathrm{~L} 1$ play a major role in defining the propensity for and severity of SC2 infection and contribute to the mechanisms by which aging and comorbid diseases contribute to the pathogenesis of COVID-19. To further understand the interactions between $\mathrm{CHI} 3 \mathrm{~L} 1$ and $\mathrm{SC} 2$, we measured the levels of circulating CHI3L1 in a cohort of normal individuals and in a cohort of patients presenting to the ED with symptoms suggestive of COVID-19. These studies support our speculations in a number of ways. First, the levels of circulating CHI3L1 in patients in the ED cohort that were infected with SC2 and patients with comorbid diseases were significantly greater than in the normal healthy controls. In accord with what has been reported in the literature $(59,80)$, when the ED cohort patients were evaluated as a group, the levels of circulating $\mathrm{CHI} 3 \mathrm{~L} 1$ were increased in patients that were elderly, had hypertension, had comorbid diseases or required hospitalization. Importantly, within the COVID-19 positive ED patients the levels of circulating CHI3L1 were statistically increased in the 
patients that were elderly, had hypertension or other comorbid diseases and or required hospitalization. These observations support the concept that SC2 co-opts the CHI3L1 axis to augment viral infection and foster its disease manifestations. They also raise the interesting possibility that quantification of the levels of circulating CHI3L1 can be useful in assessing the severity and need for hospital admission of patients presenting with COVID-19. Additional experimentation will be required to assess this speculation and further understand the relationships between CHI3L1 and COVID-19.

\section{Methods}

\section{Genetically modified mice}

Lung-specific $\mathrm{CHI} 3 \mathrm{~L} 1$ overexpressing transgenic mice in which $\mathrm{CHI} 3 \mathrm{~L} 1$ was targeted to the lung with the CC10 promoter (Chi3l1 Tg) have been generated and characterized by our laboratory as previously described $(34,81)$. These mice were between $6-12$ weeks old when used in these studies. All animals were humanely anesthetized with Ketamine/Xylazine (100mg/10mg/kg/mouse) before any intervention. The protocols that were used in these studies were evaluated and approved by the Institutional Animal Care and Use Committee (IACUC) at Brown University.

\section{Western blot analysis}

Protein lysates from macrophages and whole mouse lungs were prepared with RIPA lysis buffer (ThermoFisher Scientific, Waltham, MA, USA) containing protease inhibitor cocktail (ThermoFisher Scientific) as per the manufacturer's instructions. 20 to $30 \mu \mathrm{g}$ of lysate protein was subjected to electrophoresis on a 4-15\% gradient mini-Protean TGX gel (Bio-Rad, Hercules, CA, USA). It was then transferred to a membrane using a semidry method with a Trans-Blot Turbo Transfer System (Bio-Rad). The membranes were then blocked with Tris-buffered saline with 
Tween20 (TBST) with 5\% non-fat milk for 1 hour at room temperature. After blocking, the membranes were incubated with the primary antibodies overnight at $4^{\circ} \mathrm{C}$ in TBST and $5 \%$ BSA. Th primary antibodies used in this study are: $\alpha$-ACE2 (Abcam, ERR4435(2), ab108252), $\alpha$ TMPRSS2 (Abcam, EPR3861, ab92323), $\alpha$-CTSL (R\&D Systems, AF1515). $\beta$-actin (Santa Cruz Biotechnology, Sc47778). The membranes were then washed 3 times with TBST and incubated with secondary antibodies in TBST, $5 \%$ non-fat milk for 1 hour at room temperature. After 3 additional TBST washes, Supersignal West Femto Maximum Sensitivity Substrate Solution (Thermofisher Scientific) was added to the membrane and immunoreactive bands were detected by using a ChemiDoc (Bio-Rad) imaging system.

\section{RNA extraction and Real-Time PCR}

Total cellular RNA was obtained using TRIzol reagent (ThermoFisher Scientific) followed by RNA extraction using RNeasy Mini Kit (Qiagen, Germantown, MD) according to the manufacturer's instructions. mRNA was measured and used for real time (RT)-PCR as described previously (34, 36). The primer sequences used in these studies are summarized in supplemental Table S3. Ct values of the test genes were normalized to internal housekeeping genes such as $\beta$-actin, GAPDH or RPL13a.

\section{Immunohistochemistry}

Formalin-fixed paraffin embedded (FFPE) lung tissue blocks were serially sectioned at $5 \mu \mathrm{m}$ thickness and mounted on glass slides. After deparaffinization and dehydration, heat-induced epitope retrieval was performed by boiling the samples in a steamer for 30 minutes in antigen unmasking solution (Abcam, antigen retrieval buffer, 100x citrate buffer $\mathrm{pH}: 6.0$ ). To prevent nonspecific protein binding, all sections were blocked in a ready-to-use serum free protein blocking solution (Dako/Agilent, Santa Clara, CA) for 10 minutes at room temperature. The 
sections were then incubated with primary antibodies ( $\alpha$-Ace2 (R\&D Systems, AF3437), $\alpha$ Tmprss2 (Abcam, ab92323), $\alpha$-Ctsl (R\&D Systems, AF1515), $\alpha$-CC10 (Santa Cruz Biotechnology, sc-365992), $\alpha$-SPC (Abcam, ab90716), $\alpha$-CD31 (BD Pharmingen, 550274), $\alpha$ transgelin (Abcam, ab14106)) overnight at $4^{\circ} \mathrm{C}$. After three washings, fluorescence-labeled secondary antibodies were incubated for 1 hour at room temperature. The sections were then counterstained with DAPI and cover slips were added.

\section{Double label immunohistochemistry}

Double label immunohistochemistry was employed as previously described by our lab (34)

\section{Generation of monoclonal antibodies against CHI3L1 (FRG)}

The murine monoclonal anti-CHI3L1 antibody (FRG) was generated using peptide antigen (amino acid 223-234 of human CHI3L1) as immunogen through Abmart Inc (Berkeley Heights, NJ). This monoclonal antibody specifically detects both human and mouse CHI3L1 with high affinity (kd $\left.\approx 1.1 \times 10^{-9}\right)$. HEK-293T cells were transfected with the FRG construct using Lipofectamine ${ }^{\mathrm{TM}} 3000$ (Invitrogen, \# L3000015). Supernatant was collected for 7 days and the antibody was purified using a protein A column (ThermoFisher scientific, \# 89960). Ligand binding affinity and sensitivity were assessed using ELISA techniques.

\section{SARS-CoV-2 pseudovirus infection}

Pseudotyped SARS-CoV-2 virus which has a lentiviral core expressing GFP but with the SARSCoV-2 spike protein (expressing D614 or G614 S protein) on its envelope were obtained from COBRE Center for Stem Cells and Aging established at Brown University and Rhode Island Hospital. A plasmid expressing VSV-G protein instead of the S protein was used to generate a pantropic control lentivirus. SARS-CoV-2 pseudovirus or VSV-G lentivirus were used to spin- 
infect Calu-3 cells in a 12-well plate $\left(931 \mathrm{~g}\right.$ for 2 hours at $30^{\circ} \mathrm{C}$ in the presence of $8 \mathrm{~g} / \mathrm{ml}$ polybrene). Fluorescence microscopic images were taken $18 \mathrm{~h}$ after infection. Flow cytometry analysis of GFP (+) cells was carried out $48 \mathrm{~h}$ after infection on a BD LSRII flow cytometer and with the FlowJo software.

\section{Assessment of the effects of CHI3L1 on S protein-ACE2 binding and S protein processing}

The effects of CHI3L1 on the binding of ACE2 and S protein were evaluated using Calu-3 cells and recombinant S protein. In brief, Calu-3 cells were incubated with vehicle (PBS) or rCHI3L1 (500ng/ml) for 24 hrs, recombinant S protein from SARS-COV2 (GeneScript, \# Z03481-100) was added to the cells and further incubated for $2 \mathrm{hrs}$. The cells were then harvested and subjected to co-immunoprecipitation (Co-IP) and immunoblot assays as described by our laboratory (65). The impact of CHI3L1 on the cellular processing of S-protein was also assessed using Calu-3 cells in vitro. In these experiments, cells were incubated with vehicle (PBS) or $\mathrm{rCHI} 3 \mathrm{~L} 1$ (500ng/ml) for 24 hrs, harvested and lysates were produced. The lysates were then incubated with recombinant $\mathrm{S}$ protein for $2 \mathrm{hrs}$ and the un-cleaved $\mathrm{S}$ and cleaved $\mathrm{S} 1$ and $\mathrm{S} 2$ proteins were evaluated by Western immunoblot analysis using anti-SARS-CoV-2 Spike antibody (Proscience, \#3525).

\section{Generation of WT and mutant forms of recombinant CHI3L1}

WT CHI3L1-histidine tagged pcDNA was obtained from the MedImmune Inc (Gaithersburg, MD). The putative serine or tyrosine phosphorylation sites of CHI3L1 located between 230-239 were mutated using methods of site-directed mutagenesis. The plasmids containing WT and 4 mutant forms of CHI3L1 (M230 (Ser-Arg), M235 (Ser-Arg), M237 (Thr-Phe), M239 (Tyr-Arg)) were transfected to HEK293 cells $\left(\mathrm{ATCC}^{\circledR} \mathrm{CRL}-1573^{\mathrm{TM}}\right.$ ) and each recombinant protein was purified

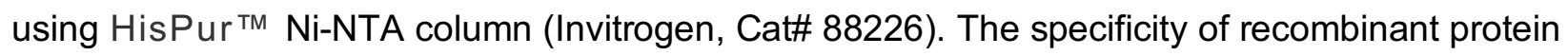
was further validated by SDS-PAGE and Western blot evaluations. 


\section{Biobank and healthy donor samples}

Deidentified COVID-19 (+) and (-) human plasma samples were received from the LifespanBrown COVID-19 Biobank at Rhode Island Hospital (Providence, Rhode Island), Brown University. Normal, healthy, COVID-19 (-) samples were commercially available form Lee BioSolutions (991-58-PS-1, Lee BioSolutions, Maryland Heights, MO).

\section{Clinical variables and COVID Severity Score}

Available deidentified clinical variables were collected from patients and from chart review during their time in the emergency department (ED). The following categorized variables were collected including chronic diseases; chronic lung disease (such as asthma, COPD or emphysema), chronic kidney disease, chronic neurologic disease (such as Parkinsons, Alzheimers, Multiple sclerosis), heart disease, high blood pressure, autoimmune diseases (such as lupus or rheumatoid arthritis), HIVIAIDS, active cancer (currently on treatment), previous stroke, overweight or obese (overweight for height $>99$ percentile). Symptoms were also assessed including; breathing difficulty or shortness of breath, fever, cough, change in taste or smell, rash, gastrointestinal symptoms (such as abdominal pain, vomiting, diarrhea), neurologic symptom (including stroke-like symptoms), sore throat and chest pain. A COVID-19 severity score was assigned to each individual ED patient based on their COVID-19 infection and their clinical status. This included their comorbid diseases, symptoms, discharge or admission, oxygen treatment or ICU transfer as outlined in Table S2.

\section{Quantification and Statistical analysis}

Statistical evaluations were undertaken with SPSS or GraphPad Prism software. As appropriate, groups were compared with 2-tailed Student's $t$ test or with nonparametric Mann-Whitney U test. Values are expressed as mean \pm SEM. One-way ANOVA or nonparametric Kruskal-Wallis tests 
were used for multiple group comparisons. Statistical significance was defined as a level of $P<$ 0.05 .

\section{Study Approval}

The IRB study protocol "Pilot Study Evaluating Cytokine Profiles in COVID-19 Patient Samples" did not meet the definition of human subject research by either the Brown University or the Rhode Island Hospital IRBs. All animal procedures and experiments were conducted according to protocols approved by the Institutional Animal Care Use Committee at Brown University. 


\section{Author Contributions}

Conception and design: SK, JAE, CGL, BM, BA; Generation of experimental resources and data collection: SK, BM, CHH, BA, CML, WED, KH, OL, MJK, HJS, EM; Analysis and interpretation: SK, BA, BM, CML, CHH, JM, EM, CGL, JAE; Drafting the manuscript for important intellectual content: JAE, CGL

\section{Acknowledgements}

This work was supported by National Institute of Health (NIH) grants U01 HL108638 (JAE), PO1 HL114501(JAE), and R01 HL115813 (CGL) from NHLBI and RO1 AG053495 (MJK) from NIA and USAMRMC W81XWH-17-1-0196 (JAE) from Department of Defense. This work was also supported by COVID-19 Research Seed Grant from Brown University (CGL and JAE). The Lentivirus Construct Core of the COBRE Center for Stem Cells and Aging was supported by a grant from the NIH (P20 GM119943 to OL). We thank Dr. Toshiyuki Okada and Professor Shigeaki Saitoh (Institute of Life Science, Kurume University, Japan) for helpful discussions on activation mechanism of CHI3L1.

\section{Competing Interests}

Disclosures: Jack A Elias is a cofounder of Elkurt Pharmaceuticals that develops therapeutics based on the 18 glycosyl hydrolase gene family. 


\section{REFERENCES}

1. Chen N, Zhou M, Dong X, Qu J, Gong F, Han Y, et al. Epidemiological and clinical characteristics of 99 cases of 2019 novel coronavirus pneumonia in Wuhan, China: a descriptive study. Lancet. 2020;395(10223):507-13.

2. Huang C, Wang Y, Li X, Ren L, Zhao J, Hu Y, et al. Clinical features of patients infected with 2019 novel coronavirus in Wuhan, China. Lancet. 2020;395(10223):497-506.

3. Li Q, Guan X, Wu P, Wang X, Zhou L, Tong Y, et al. Early Transmission Dynamics in Wuhan, China, of Novel Coronavirus-Infected Pneumonia. $N$ Engl $J$ Med. 2020;382(13):1199-207.

4. Wang D, Hu B, Hu C, Zhu F, Liu X, Zhang J, et al. Clinical Characteristics of 138 Hospitalized Patients With 2019 Novel Coronavirus-Infected Pneumonia in Wuhan, China. JAMA. 2020.

5. Guan WJ, Ni ZY, Hu Y, Liang WH, Ou CQ, He JX, et al. Clinical Characteristics of Coronavirus Disease 2019 in China. N Engl J Med. 2020;382(18):1708-20.

6. Wu Z, and McGoogan JM. Characteristics of and Important Lessons From the Coronavirus Disease 2019 (COVID-19) Outbreak in China: Summary of a Report of 72314 Cases From the Chinese Center for Disease Control and Prevention. JAMA. 2020.

7. CSSE JHU. COVID-19 Dashboard by the Center for Systems Science and Engineering (CSSE) at Johns Hopkins University. https://coronavirusjhuedu/maphtml [Access date Jan 1, 2021]. 2021.

8. Lake MA. What we know so far: COVID-19 current clinical knowledge and research. Clin Med (Lond). 2020;20(2):124-7.

9. Inciardi RM, Solomon SD, Ridker PM, and Metra M. Coronavirus 2019 Disease (COVID19), Systemic Inflammation, and Cardiovascular Disease. J Am Heart Assoc. 2020;9(16):e017756.

10. Gupta A, Madhavan MV, Sehgal K, Nair N, Mahajan S, Sehrawat TS, et al. Extrapulmonary manifestations of COVID-19. Nat Med. 2020;26(7):1017-32.

11. Richardson S, Hirsch JS, Narasimhan M, Crawford JM, McGinn T, Davidson KW, et al. Presenting Characteristics, Comorbidities, and Outcomes Among 5700 Patients Hospitalized With COVID-19 in the New York City Area. JAMA. 2020.

12. Phua J, Weng L, Ling L, Egi M, Lim CM, Divatia JV, et al. Intensive care management of coronavirus disease 2019 (COVID-19): challenges and recommendations. Lancet Respir Med. 2020;8(5):506-17.

13. Ackermann M, Verleden SE, Kuehnel M, Haverich A, Welte T, Laenger F, et al. Pulmonary Vascular Endothelialitis, Thrombosis, and Angiogenesis in Covid-19. N Engl J Med. 2020.

14. Schaller T, Hirschbuhl K, Burkhardt K, Braun G, Trepel M, Markl B, et al. Postmortem Examination of Patients With COVID-19. JAMA. 2020.

15. Bourgonje AR, Abdulle AE, Timens W, Hillebrands JL, Navis GJ, Gordijn SJ, et al. Angiotensin-converting enzyme 2 (ACE2), SARS-CoV-2 and the pathophysiology of coronavirus disease 2019 (COVID-19). J Pathol. 2020.

16. Verity R, Okell LC, Dorigatti I, Winskill P, Whittaker C, Imai N, et al. Estimates of the severity of coronavirus disease 2019: a model-based analysis. Lancet Infect Dis. 2020;20(6):669-77.

17. Bernabeu-Wittel M, Ternero-Vega JE, Diaz-Jimenez P, Conde-Guzman C, Nieto-Martin MD, Moreno-Gavino L, et al. Death risk stratification in elderly patients with covid-19. A comparative cohort study in nursing homes outbreaks. Arch Gerontol Geriatr. 2020;91:104240.

18. Li T, Lu L, Zhang W, Tao Y, Wang L, Bao J, et al. Clinical characteristics of 312 hospitalized older patients with COVID-19 in Wuhan, China. Arch Gerontol Geriatr. 2020;91:104185. 
19. Zhang H, Rostami MR, Leopold PL, Mezey JG, O'Beirne SL, Strulovici-Barel Y, et al. Expression of the SARS-CoV-2 ACE2 Receptor in the Human Airway Epithelium. Am J Respir Crit Care Med. 2020.

20. Epidemiology NCPER. The epidemiological characteristics of an outbreak of 2019 novel coronavirus diseases (COVID-19) in China. Zhonghua Liu Xing Bing Xue Za Zhi 2020;41:145-51.

21. Millet JK, and Whittaker GR. Host cell proteases: Critical determinants of coronavirus tropism and pathogenesis. Virus Res. 2015;202:120-34.

22. Coutard B, Valle C, de Lamballerie X, Canard B, Seidah NG, and Decroly E. The spike glycoprotein of the new coronavirus 2019-nCoV contains a furin-like cleavage site absent in CoV of the same clade. Antiviral Res. 2020;176:104742.

23. Hoffmann M, Kleine-Weber H, Schroeder S, Kruger N, Herrler T, Erichsen S, et al. SARSCoV-2 Cell Entry Depends on ACE2 and TMPRSS2 and Is Blocked by a Clinically Proven Protease Inhibitor. Cell. 2020;181(2):271-80 e8.

24. Letko M, Marzi A, and Munster V. Functional assessment of cell entry and receptor usage for SARS-CoV-2 and other lineage B betacoronaviruses. Nat Microbiol. 2020;5(4):562-9.

25. Lukassen S, Chua RL, Trefzer T, Kahn NC, Schneider MA, Muley T, et al. SARS-CoV-2 receptor ACE2 and TMPRSS2 are primarily expressed in bronchial transient secretory cells. EMBO J. 2020;39(10):e105114.

26. Baig AM, Khaleeq A, Ali U, and Syeda H. Evidence of the COVID-19 Virus Targeting the CNS: Tissue Distribution, Host-Virus Interaction, and Proposed Neurotropic Mechanisms. ACS Chem Neurosci. 2020;11(7):995-8.

27. Bunyavanich S, Do A, and Vicencio A. Nasal Gene Expression of Angiotensin-Converting Enzyme 2 in Children and Adults. JAMA. 2020.

28. de Wilde AH, Snijder EJ, Kikkert M, and van Hemert MJ. Host Factors in Coronavirus Replication. Curr Top Microbiol Immunol. 2018;419:1-42.

29. Maggi E, Canonica GW, and Moretta L. COVID-19: Unanswered questions on immune response and pathogenesis. J Allergy Clin Immunol. 2020;146(1):18-22.

30. Kikkert M. Innate Immune Evasion by Human Respiratory RNA Viruses. J Innate Immun. 2020;12(1):4-20.

31. Lee CG. Chitin, chitinases and chitinase-like proteins in allergic inflammation and tissue remodeling. Yonsei Med J. 2009;50(1):22-30.

32. Lee CG, Da Silva CA, Dela Cruz CS, Ahangari F, Ma B, Kang MJ, et al. Role of chitin and chitinase/chitinase-like proteins in inflammation, tissue remodeling and injury. Annu Rev Physiol. 2011;73:479-501.

33. Lee CG, and Elias JA. Role of breast regression protein-39/YKL-40 in asthma and allergic responses. Allergy Asthma Immunol Res. 2010;2(1):20-7.

34. Lee CG, Hartl D, Lee GR, Koller B, Matsuura H, Da Silva CA, et al. Role of breast regression protein 39 (BRP-39)/chitinase 3-like-1 in Th2 and IL-13-induced tissue responses and apoptosis. The Journal of experimental medicine. 2009;206(5):1149-66.

35. Funkhouser JD, and Aronson NN. Chitinase family GH18: evolutionary insights from the genomic history of a diverse protein family. BMC Evol Biol. 2007;7:96.

36. Sohn MH, Kang MJ, Matsuura H, Bhandari V, Chen NY, Lee CG, et al. The chitinase-like proteins breast regression protein-39 and $\mathrm{YKL}-40$ regulate hyperoxia-induced acute lung injury. Am J Respir Crit Care Med. 2010;182(7):918-28.

37. Dela Cruz CS, Liu W, He CH, Jacoby A, Gornitsky A, Ma B, et al. Chitinase 3-like-1 (Chi3l1) Regulation of Streptococcus pneumoniae Lung Infection. Cell Host and Microbe. 2012;12(1):34-46.

38. Zhou Y, Peng H, Sun H, Peng X, Tang C, Gan Y, et al. Chitinase 3-like 1 suppresses injury and promotes fibroproliferative responses in Mammalian lung fibrosis. Science translational medicine. 2014;6(240):240ra76. 
39. Garnero P, Mazieres B, Gueguen A, Abbal M, Berdah L, Lequesne M, et al. Crosssectional association of 10 molecular markers of bone, cartilage, and synovium with disease activity and radiological joint damage in patients with hip osteoarthritis: the ECHODIAH cohort. J Rheumatol. 2005;32(4):697-703.

40. Hakala BE, White $C$, and Recklies AD. Human cartilage gp-39, a major secretory product of articular chondrocytes and synovial cells, is a mammalian member of a chitinase protein family. J Biol Chem. 1993;268(34):25803-10.

41. Johansen JS, Christoffersen P, Moller S, Price PA, and Bendtsen F. Serum YLK-40 is increased in patients with hepatic fibrosis. J Hepatology. 2000;32:911-20.

42. Johansen JS, Jensen HS, and Price PA. A new biochemical marker for joint injury. Analysis of YKL-40 in serum and synovial fluid. Br J Rheumatol. 1993;32(11):949-55.

43. Kucur M, Isman FK, Karadag B, Vural VA, and Tavsanoglu S. Serum YKL-40 levels in patients with coronary artery disease. Coron Artery Dis. 2007;18:391-6.

44. Matsuura H, Hartl D, Kang MJ, Dela Cruz CS, Koller B, Chupp GL, et al. Role of breast regression protein-39 in the pathogenesis of cigarette smoke-induced inflammation and emphysema. Am J Respir Cell Mol Biol. 2011;44(6):777-86.

45. Nordenbaek C, Johansen JS, Junker P, Borregaard N, Sorensen O, and Price PA. YKL40 , a matrix protein of specific granules in neutrophils, is elevated in serum of patients with community-acquired pneumonia requiring hospitalization. J Infect Dis. 1999;180(5):1722-6.

46. Ostergaard C, Johansen JS, Benfield T, Price PA, and Lundgren JD. YKL-40 is elevated in cerebrospinal fluid from patients with purulent meningitis. Clin Diagn Lab Immunol. 2002;9(3):598-604.

47. Ahangari F, Sood A, Ma B, Takyar S, Schuyler M, Qualls C, et al. Chitinase 3-like-1 regulates both visceral fat accumulation and asthma-like Th2 inflammation. Am J Respir Crit Care Med. 2015;191(7):746-57.

48. Ober C, Tan Z, Sun Y, Possick JD, Pan L, Nicolae R, et al. Effect of variation in CHI3L1 on serum YKL-40 level, risk of asthma, and lung function. $N$ Engl $J$ Med. 2008;358(16):1682-91.

49. Gomez JL, Crisafi GM, Holm CT, Meyers DA, Hawkins GA, Bleecker ER, et al. Genetic variation in chitinase 3 -like 1 (CHI3L1) contributes to asthma severity and airway expression of YKL-40. J Allergy Clin Immunol. 2015;136(1):51-8 e10.

50. Chupp GL, Lee CG, Jarjour N, Shim YM, Holm CT, He S, et al. A chitinase-like protein in the lung and circulation of patients with severe asthma. N Engl J Med. 2007;357(20):201627.

51. Di Rosa M, and Malaguarnera L. Chitinase 3 Like-1: An Emerging Molecule Involved in Diabetes and Diabetic Complications. Pathobiology. 2016;83(5):228-42.

52. Li K, Chen Z, Qin Y, and Wei YX. Plasm YKL-40 Levels Are Associated with Hypertension in Patients with Obstructive Sleep Apnea. Biomed Res Int. 2019;2019:5193597.

53. Kastrup J, Johansen JS, Winkel P, Hansen JF, Hildebrandt P, Jensen GB, et al. High serum YKL-40 concentration is associated with cardiovascular and all-cause mortality in patients with stable coronary artery disease. Eur Heart J. 2009;30(9):1066-72.

54. Schernthaner $\mathrm{GH}$, Hobaus $\mathrm{C}$, and Brix J. YKL-40 and its complex association with metabolic syndrome, obesity, and cardiovascular disease. Anatol $J$ Cardiol. 2016;16(12):959.

55. Imai Y, Kuba K, Rao S, Huan Y, Guo F, Guan B, et al. Angiotensin-converting enzyme 2 protects from severe acute lung failure. Nature. 2005;436(7047):112-6.

56. Li Y, Zeng Z, Cao Y, Liu Y, Ping F, Liang M, et al. Angiotensin-converting enzyme 2 prevents lipopolysaccharide-induced rat acute lung injury via suppressing the ERK1/2 and NF-kappaB signaling pathways. Sci Rep. 2016;6:27911. 
57. Ye R, and Liu Z. ACE2 exhibits protective effects against LPS-induced acute lung injury in mice by inhibiting the LPS-TLR4 pathway. Exp Mol Pathol. 2020;113:104350.

58. Yang XH, Deng W, Tong Z, Liu YX, Zhang LF, Zhu H, et al. Mice transgenic for human angiotensin-converting enzyme 2 provide a model for SARS coronavirus infection. Comp Med. 2007;57(5):450-9.

59. Johansen JS, Pedersen AN, Schroll M, Jorgensen T, Pedersen BK, and Bruunsgaard H. High serum YKL-40 level in a cohort of octogenarians is associated with increased risk of all-cause mortality. Clin Exp Immunol. 2008;151(2):260-6.

60. Becker RC. COVID-19-associated vasculitis and vasculopathy. J Thromb Thrombolysis. 2020;50(3):499-511.

61. Lee CG, Herzog EL, Ahangari F, Zhou Y, Gulati M, Lee CM, et al. Chitinase 1 is a biomarker for and therapeutic target in scleroderma-associated interstitial lung disease that augments TGF-beta1 signaling. J Immunol. 2012;189(5):2635-44.

62. Zhou Y, He CH, Yang DS, Nguyen T, Cao Y, Kamle S, et al. Galectin-3 Interacts with the CHI3L1 Axis and Contributes to Hermansky-Pudlak Syndrome Lung Disease. J Immunol. 2018;200(6):2140-53.

63. Kang MJ, Lee CG, Lee JY, Dela Cruz CS, Chen ZJ, Enelow R, et al. Cigarette smoke selectively enhances viral PAMP- and virus-induced pulmonary innate immune and remodeling responses in mice. J Clin Invest. 2008;118(8):2771-84.

64. Kang MJ, Yoon CM, Kim BH, Lee CM, Zhou Y, Sauler M, et al. Suppression of NLRX1 in chronic obstructive pulmonary disease. J Clin Invest. 2015;125(6):2458-62.

65. He CH, Lee CG, Dela Cruz CS, Lee CM, Zhou Y, Ahangari F, et al. Chitinase 3-like 1 regulates cellular and tissue responses via IL-13 receptor alpha2. Cell reports. 2013;4(4):830-41.

66. Kim DH, Park HJ, Lim S, Koo JH, Lee HG, Choi JO, et al. Regulation of chitinase-3-like-1 in T cell elicits Th1 and cytotoxic responses to inhibit lung metastasis. Nat Commun. 2018;9(1):503.

67. Lee AJ, and Ashkar AA. The Dual Nature of Type I and Type II Interferons. Front Immunol. 2018;9:2061.

68. Vasarmidi E, Tsitoura E, Spandidos DA, Tzanakis N, and Antoniou KM. Pulmonary fibrosis in the aftermath of the COVID-19 era (Review). Exp Ther Med. 2020;20(3):2557-60.

69. Umezawa H, Hamada M, Suhara Y, Hashimoto T, and Ikekawa T. Kasugamycin, a new antibiotic. Antimicrob Agents Chemother (Bethesda). 1965;5:753-7.

70. Gopinath S, Kim MV, Rakib T, Wong PW, van Zandt M, Barry NA, et al. Topical application of aminoglycoside antibiotics enhances host resistance to viral infections in a microbiotaindependent manner. Nat Microbiol. 2018;3(5):611-21.

71. Tada S, Hakamada T, Mori O, and Yamazaki Y. [Use of kasugamycin in urinary tract infection, especially against Pseudomonas aeruginosa]. Hinyokika Kiyo. 1968;14(1):50-6.

72. USEPA. Human Health Risk Assessment for Proposed Food Uses of the Fungicide Kasugamycin on Importing Fruiting Vegetables. Health Effects Division. 2005;Available from, as of Novermber 2006: https://www.federalregister.gov/documents/2014/08/29/2014-20502/kasugamycinpesticide-tolerances.

73. Wiernik PH. Alvocidib (flavopiridol) for the treatment of chronic lymphocytic leukemia. Expert Opin Investig Drugs. 2016;25(6):729-34.

74. Ma B, Herzog EL, Moore M, Lee CM, Na SH, Lee CG, et al. RIG-like Helicase Regulation of Chitinase 3-like 1 Axis and Pulmonary Metastasis. Sci Rep. 2016;6:26299.

75. Nelemans T, and Kikkert M. Viral Innate Immune Evasion and the Pathogenesis of Emerging RNA Virus Infections. Viruses. 2019;11(10). 
76. Arunachalam PS, Wimmers F, Mok CKP, Perera R, Scott M, Hagan T, et al. Systems biological assessment of immunity to mild versus severe COVID-19 infection in humans. Science. 2020;369(6508):1210-20.

77. Hadjadj J, Yatim N, Barnabei L, Corneau A, Boussier J, Smith N, et al. Impaired type I interferon activity and inflammatory responses in severe COVID-19 patients. Science. 2020;369(6504):718-24.

78. Baric RS. Emergence of a Highly Fit SARS-CoV-2 Variant. New England Journal of Medicine. 2020.

79. Korber B, Fischer WM, Gnanakaran S, Yoon H, Theiler J, Abfalterer W, et al. Tracking Changes in SARS-CoV-2 Spike: Evidence that D614G Increases Infectivity of the COVID19 Virus. Cell. 2020;182(4):812-27.e19.

80. Xu T, Zhong C, Wang A, Guo Z, Bu X, Zhou Y, et al. YKL-40 is a novel biomarker for predicting hypertension incidence among prehypertensive subjects: A population-based nested case-control study in China. Clin Chim Acta. 2017;472:146-50.

81. Lee CM, He CH, Nour AM, Zhou Y, Ma B, Park JW, et al. IL-13Ralpha2 uses TMEM219 in chitinase 3-like-1-induced signalling and effector responses. Nat Commun. 2016;7:12752. 


\section{FIGURE LEGENDS}

Fig. 1. CHI3L1 stimulates pulmonary ACE2 and SPP. 8-week-old WT (-) and Chi3l1 Tg (+) mice were sacrificed after 2 weeks of transgene induction with Doxycycline. The levels of Ace2 and SPP mRNA and protein in the lungs from WT and Chi3l1 Tg mice were evaluated using lung lysates and paraffin tissue blocks from these animals. (A) Comparisons of levels of expression of Ace2 and SPP in lungs from WT (Tg (-)) and Chi3l1 Tg (+) mice using semi-quantitative real-time RT-PCR analysis indexed to $\beta$-actin controls. (B) Western immunoblot comparisons of levels of Ace2 and SPP in lungs from WT (Tg-) and Chi3l1 Tg (+) mice. (C-D) Immunohistochemical evaluations of Ace2, Ctsl and Tmprss2 in lungs from WT and Chi3l1 Tg mice. (E) Double label IHC comparing localization of Ace2, Tmprss2 and CD31 in the lungs from Chi3l1 Tg mice. Arrows on panels $\mathrm{C}-\mathrm{E}$ indicate the stain $(+)$ cells. Each value in panel $\mathrm{A}$ is from a different animal and the mean \pm SEM are illustrated. Panels $B-E$ are representative of at least 3 separate evaluations. Ace2, murine angiotensin converting enzyme 2; Tmprss2, transmembrane serine protease 2; Ctsl, Cathepsin L. Scale bars $=100 \mu \mathrm{m} .{ }^{*} P<0.05$ (Student $t$-test).

Fig. 2. CHI3L1 stimulates ACE2 and SPP in vitro and enhances S protein processing and cellular integration. (A) Calu-3 lung epithelial cells were incubated with the noted concentrations of recombinant $(\mathrm{r}) \mathrm{CHI}$ L1 $(\mathrm{ng} / \mathrm{ml})$ or vehicle control $(\mathrm{rCHI} \mathrm{L} 1=0)$ for $24 \mathrm{hrs}$ then subjected to RTPCR to quantitate the levels of mRNA encoding ACE2 and the SPP. (B) Western blot evaluations of the dose response and kinetics of $\mathrm{CHI} 3 \mathrm{~L} 1$ stimulation of ACE2 and SPP protein accumulation in Calu-3 cells. (C) Calu-3 cells were incubated with vehicle (PBS; CHI3L1 (-)) or rCHI3L1 (500ng/ml) for $24 \mathrm{hrs,} \mathrm{recombinant} \mathrm{S} \mathrm{protein} \mathrm{of} \mathrm{SARS-COV2} \mathrm{(SC2)} \mathrm{was} \mathrm{added} \mathrm{and} \mathrm{the} \mathrm{incubation}$ continued for an additional $2 \mathrm{hrs}$. The cells were then harvested, lysates were prepared and coimmunoprecipitation (Co-IP) and immunoblot assays were undertaken. (D) Calu-3 cells were incubated with vehicle (PBS; CHI3L1 (-)) or rCHI3L1 $(500 \mathrm{ng} / \mathrm{ml})$ for $24 \mathrm{hrs}$, the cells were 
harvested, and the recombinant S protein of SARS-COV2 (SC2) was added to the lysates and the incubation continued for an additional $2 \mathrm{hrs}$. The un-cleaved S and cleaved S1 and S2 proteins were evaluated using Western immunoblotting. (E) Calu-3 cells were incubated with vehicle (rCHI3L1(-)) or the noted concentrations of rCHI3L1 for $24 \mathrm{hrs}$. They were then transfected with a pseudovirus containing the S protein (PS; D614 variant) from SC2 and a GFP expression construct and incubated for additional $24 \mathrm{hr}$ then evaluated using fluorescent microscopy. Quantification of mean fluorescent intensity (MFI) can be seen in the dot plot on the right. (F) Calu-3 cells were incubated with rCHI3L 1 or vehicle control for $48 \mathrm{hrs}$ in the presence or absence of antibody against CHI3L1 (FRG) or control antibody (IgG). Pseudovirus S (PS; D614 and G614 variants) that expressed GFP was added as noted and GFP expression was evaluated by flow cytometry. Values in panel $A$ and $E$ are mean \pm SEM. Panels $B-F$ are the representative gel, fluorescent images and FACS data obtained from at least 3 independent experiments. MFI, mean fluorescent intensity. The numbers in the panel $F$ represent $\%$ of GFP positive cells. ${ }^{*} P<0.05$, ${ }^{* *} P<0.01,{ }^{* * *} P<0.001,{ }^{* * * *} P<0.0001$ (One-Way ANOVA with post hoc Dunnett's multiple comparison test). Scale bar $=50 \mu \mathrm{m}$.

Fig. 3. Effects of a monoclonal antibody and small molecule inhibitor on CHI3L1stimulation of ACE2 and SPP in vitro and in vivo. (A-B) Calu-3 cells were stimulated with vehicle (PBS) or rCHI3L1 (250ng/ml) and treated with isotype control lgG or anti-CHI3L1 (FRG) for $48 \mathrm{hrs}$. The cells were then harvested and the levels of mRNA encoding ACE2 and SPP and ACE2 and SPP protein were evaluated by RT-PCR (A) and immunoblot assays (B). (C) WT and Chi3l1 Tg (Tg) mice were treated with lgG isotype control antibody or FRG antibody during their 2 weeks of transgene activation. The levels of mRNA encoding Ace2 and SPP were then evaluated using RT-PCR. (D) Calu-3 cells were stimulated with vehicle (PBS) or rCHI3L1 $(250 \mathrm{ng} / \mathrm{ml})$ and treated with kasugamycin or vehicle control (PBS) for $48 \mathrm{hrs}$. The cells were then 
harvested and the levels of mRNA encoding ACE2 and SPP were evaluated by RT-PCR. Each value in panels $A$ and $C-D$ is from a different animal and the mean $\pm S E M$ are illustrated. Panel $B$ is representative of two independent experiments. ${ }^{*} P<0.05,{ }^{* *} P<0.01,{ }^{* * *} P<0.001,{ }^{* * *} P<0.0001$ (One-Way ANOVA with post hoc Turkey multiple comparison test).

Fig. 4. Alterations in CHI3L1 phosphorylation modify its ability to regulate ACE2 and SPP. (A) Demonstration that $\mathrm{CHI} 3 \mathrm{~L} 1$ is a phosphoprotein. Biologically active $\mathrm{rCH} 3 \mathrm{~L} 1$ was treated with protein phosphatase 2A (PP2A) in the presence and absence of the PP2A inhibitor Okadaic acid. The alterations in CHI3L1 phosphorylation were evaluated with immunoblots using antibodies against phosphoserine or CHI3L1 controls. (B) Calu-3 cells were stimulated with a wild type (Wt) or a mutant form of $\mathrm{rCHI} 3 \mathrm{~L} 1$ ( $250 \mathrm{ng} / \mathrm{ml}$ for each; 24 hours) that could not be phosphorylated. The latter was done by generating a Serine to Arginine mutation at amino acid 230. The cells were then harvested and the levels of mRNA encoding ACE2 and SPP2 was evaluated by RT-PCR. (C-D) Calu-3 cells were transfected with pcDNA (vector only) or the plasmid containing a CHI3L1 cDNA (pCHI3L1). They were simultaneously treated with Flavopiridol (Flavo; 5nM) (C) or BMS265246 (BMS; 9nM) (D) or their vehicle controls (5\% DMSO) for 24 hrs. The cells were then harvested and the levels of mRNA encoding ACE2 and SPP were evaluated by RT-PCR. Panel A is representative Immunoblots in 3 separate experiments. The values in panels $B$ and $D$ are mean \pm SEM. Each value in panel $\mathrm{C}$ is from a different animal and the mean \pm SEM are illustrated. ${ }^{*} P<0.05,{ }^{* *} P<0.01,{ }^{* *} P<0.001,{ }^{* * *} P<0.0001$ (One-Way ANOVA with post hoc Turkey multiple comparison test).

Fig. 5. CHI3L1 is induced and regulates the expression of ACE2 and SPP in the lungs of aged mice. (A) Comparison of the levels of mRNA encoding Ace2 and SPP in lungs from 6-and 12-months old WT mice evaluated by RT-PCR. (B) Wild type mice were treated with IgG isotype 
antibody or anti-CHI3L1 (FRG) (200 $\mu \mathrm{g} /$ mouse, twice a week, i.p. injection) when the mice were between 6 and 12 months of age. At the end of this interval, the mice were sacrificed and the levels of mRNA encoding pulmonary Ace 2 and SPP were evaluated by RT-PCR. Each value in panels $A$ and $B$ is from a different animal and the mean \pm SEM are illustrated. ${ }^{*} P<0.05,{ }^{* *} P<0.01$ (Mann-Whitney U test).

Fig. 6. The levels of CHI3L1 in the circulation of patients with risk factors for COVID-19. The levels of CHI3L1 were assessed by ELISA using plasma from normals without comorbid diseases and patients presenting for emergency department evaluation. The values that were obtained were compared to the clinical features of the patients and the course of their diseases. ER, emergency room; CM, comorbid disease; HT, hypertension; COV, COVID-19; Dis, discharge; Adm, admission; ICU, intensive care unit. Each value is from a different individual and the mean \pm SEM are illustrated. ${ }^{*} P<0.05,{ }^{* *} P<0.01,{ }^{* * *} P<0.001,{ }^{* * *} P<0.0001$, ns $=$ not significant (Panels A, B, F: Kruskal-Walis with Dunn's post hoc test for multiple comparisons; Panels C-E and G-J: Mann-Whitney $U$ test). Global $P$ value of panel F was 0.0002 . 


\section{Figure 1}

A

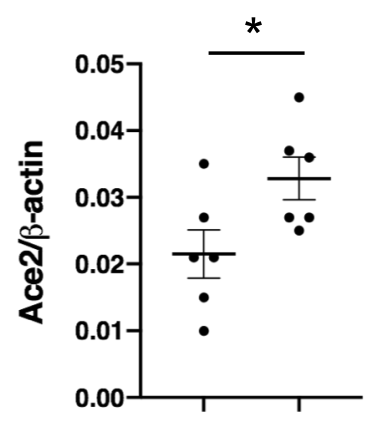

Chi3l1 Tg - +

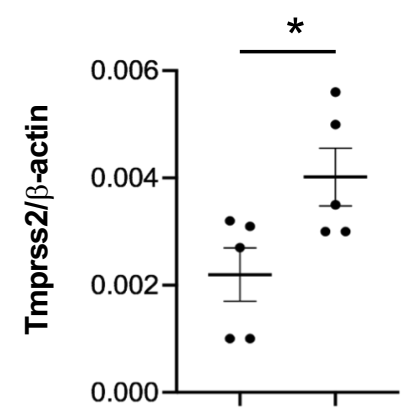

Chi3l1 Tg - +

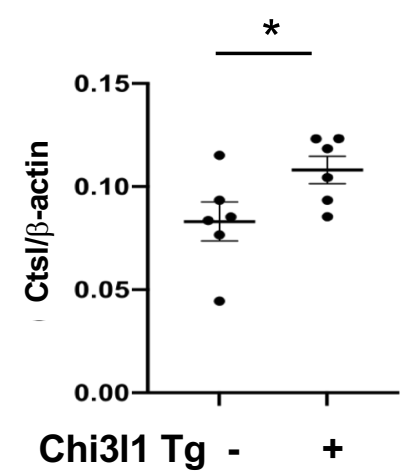

Chi3l1 Tg - +
B

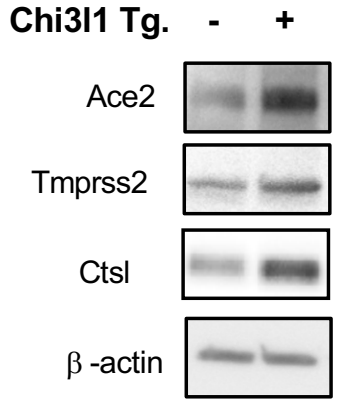

C

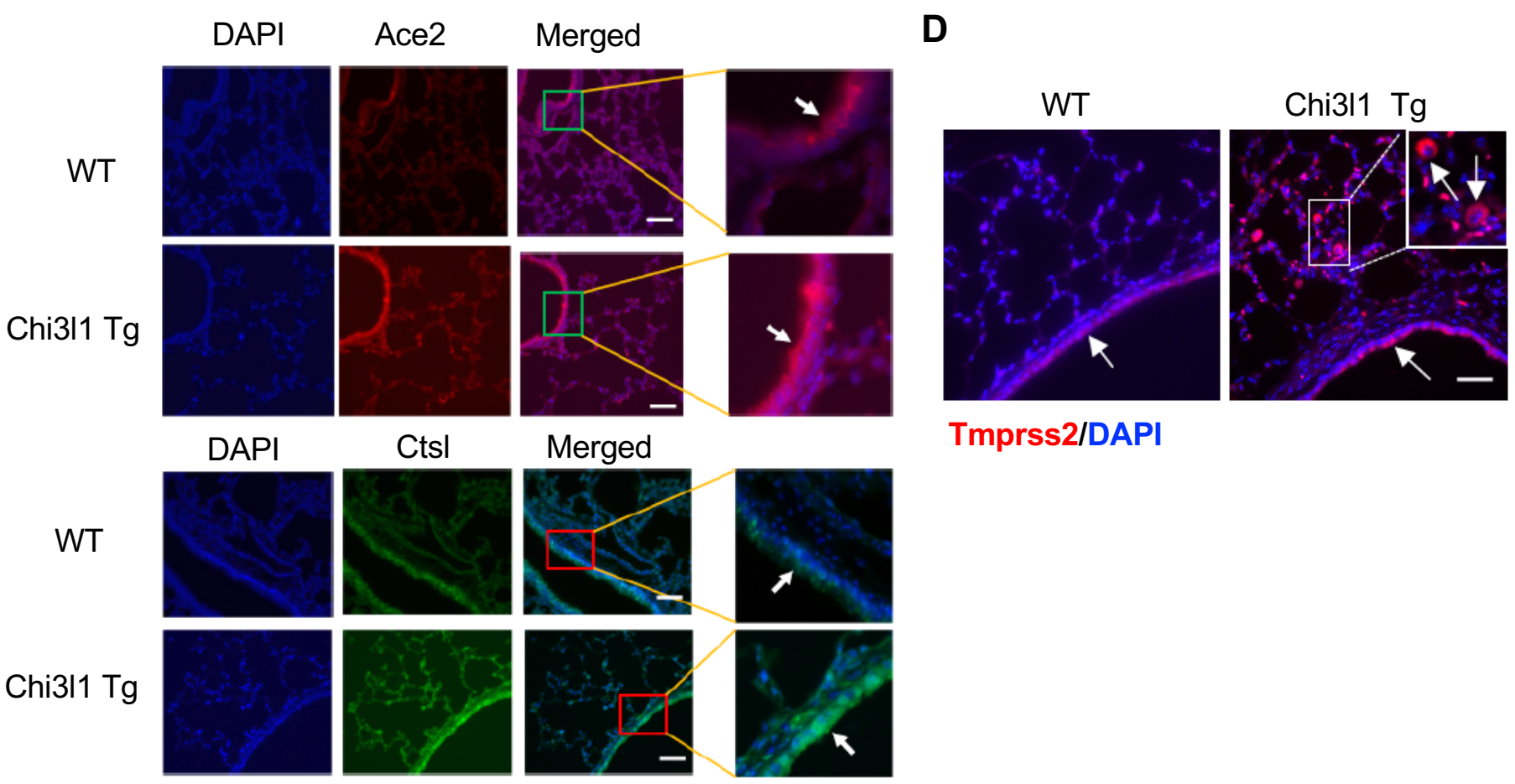

E

Ace2

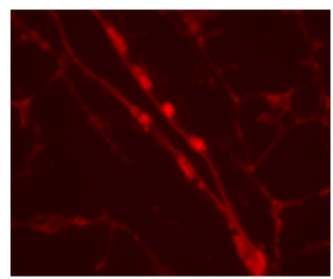

Tmprss2
CD31

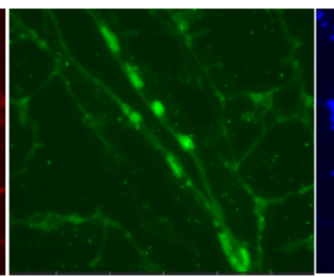

CD31
DAPI

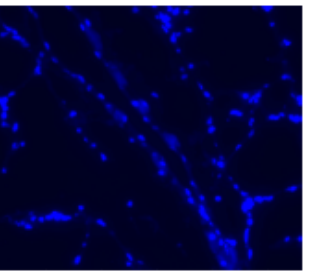

DAPI

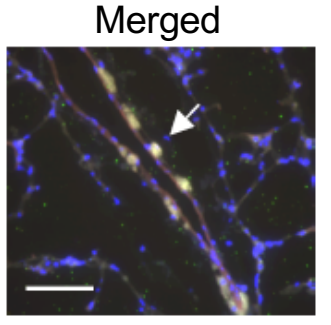

Merged
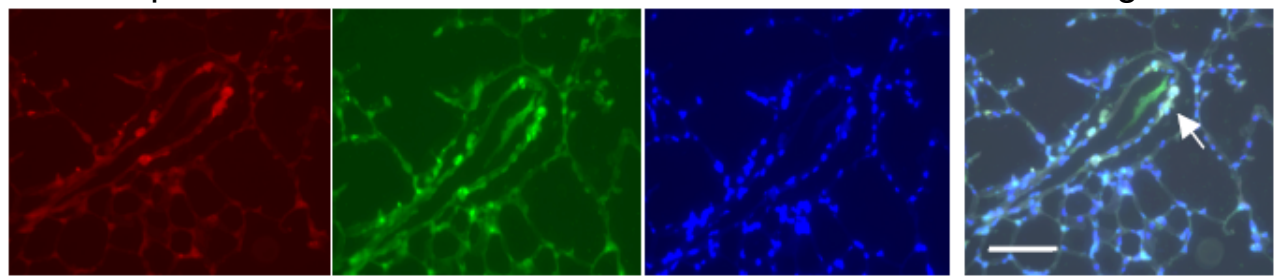


\section{Figure 2}

A

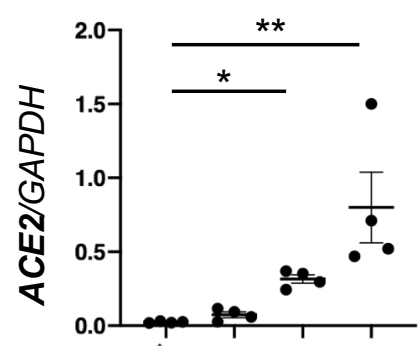

rCHI3L1 0125250500

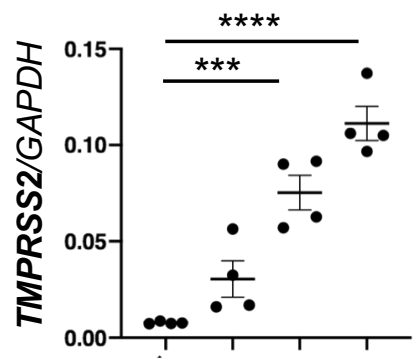

rCHI3L1 0125250500

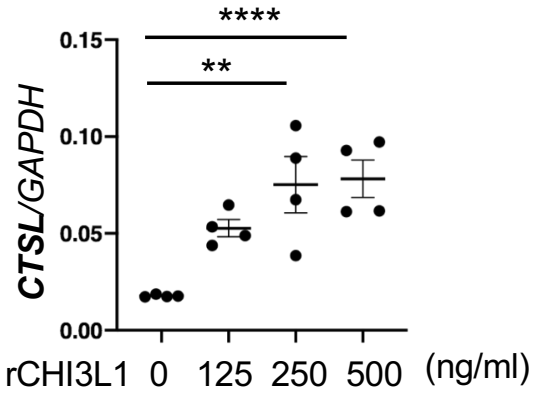

D
B

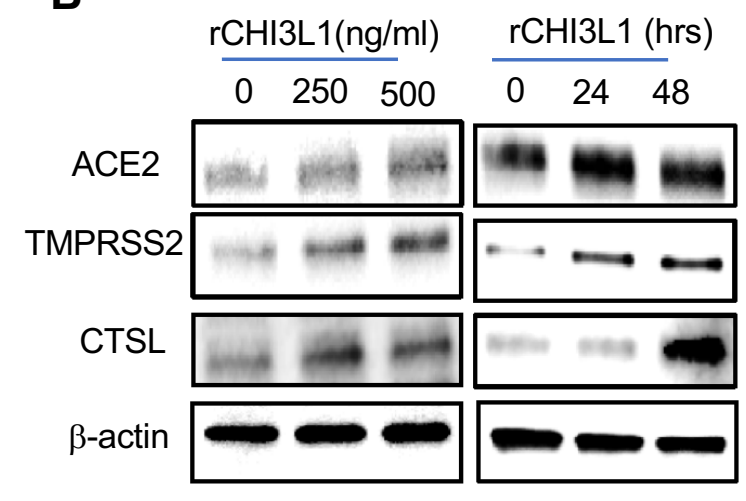

C

Spike S - - + + rCHI3L1 - + +

IP: a-Spike S

IB: $\alpha$-ACE2

IB: $\alpha$-ACE2

IB: $\alpha-\beta$-actin
Spike S - - + + rCHI3L1 - + - +

Spike S1

Spike S2

Spike S

$\beta$-actin

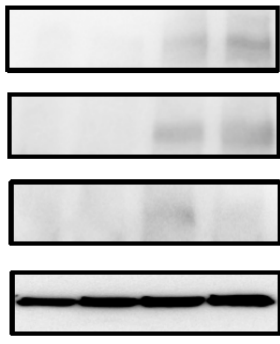

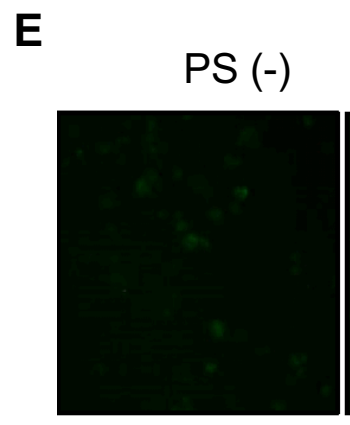

rCHI3L1
Pseudovirus-S (PS +)
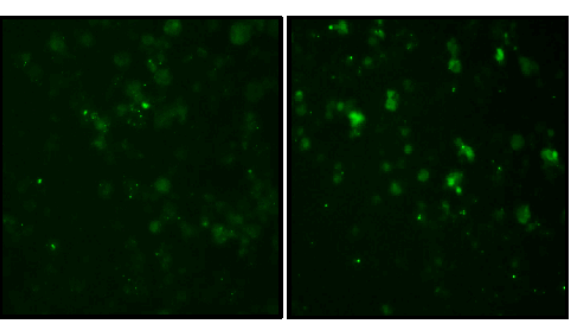

250

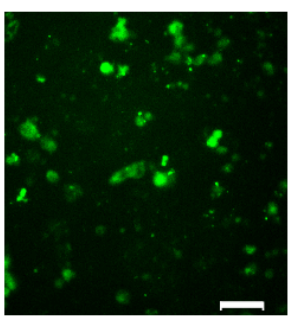

500

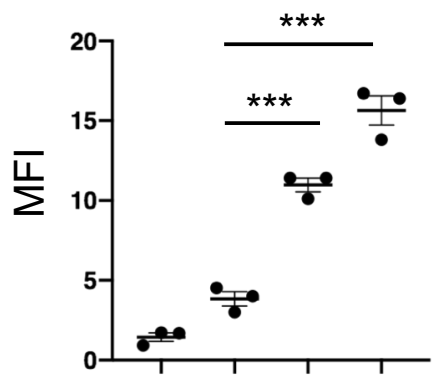

PS - + + + rCHI3L1 - $\quad 250500$
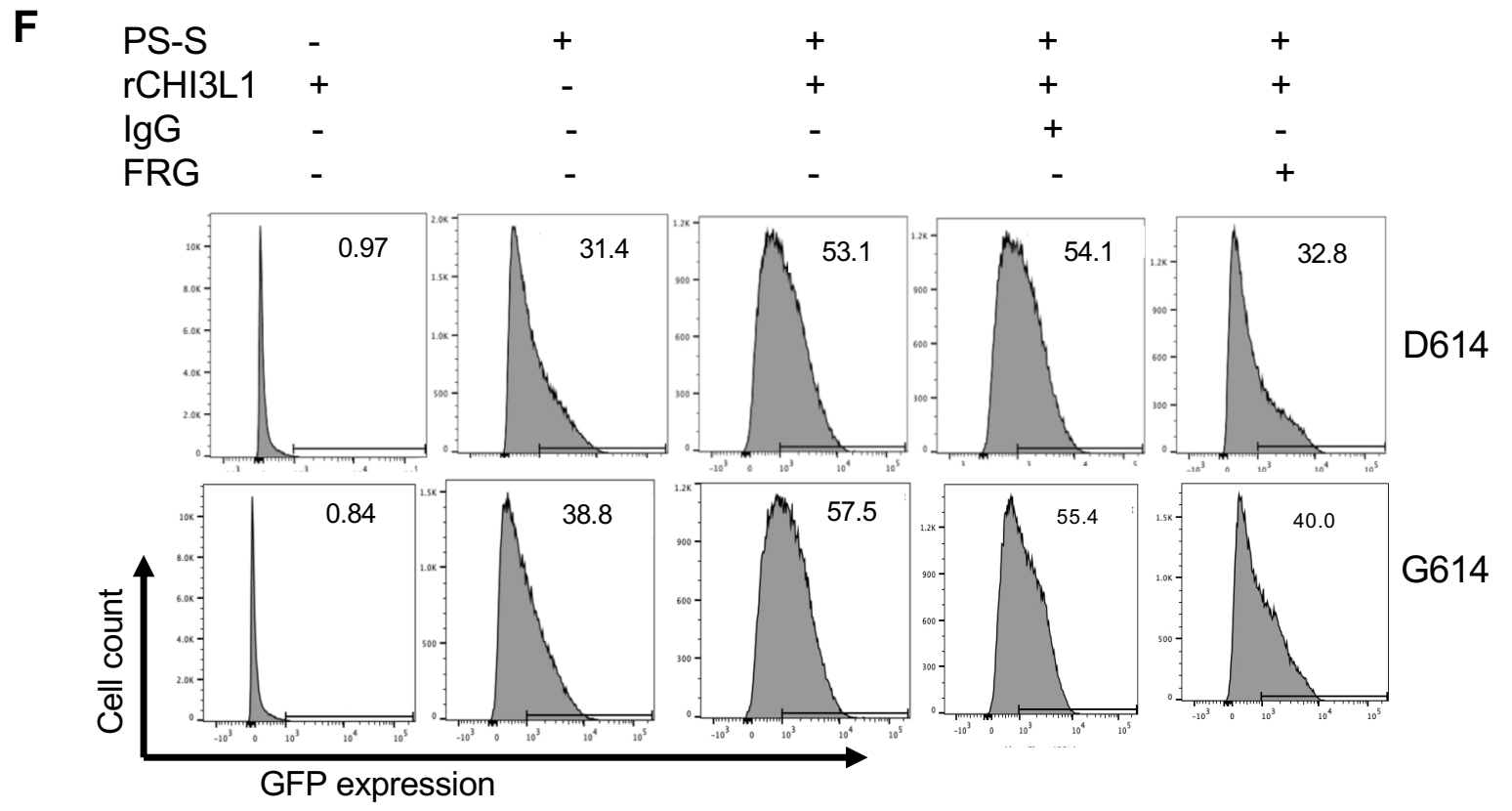
Figure 3

A
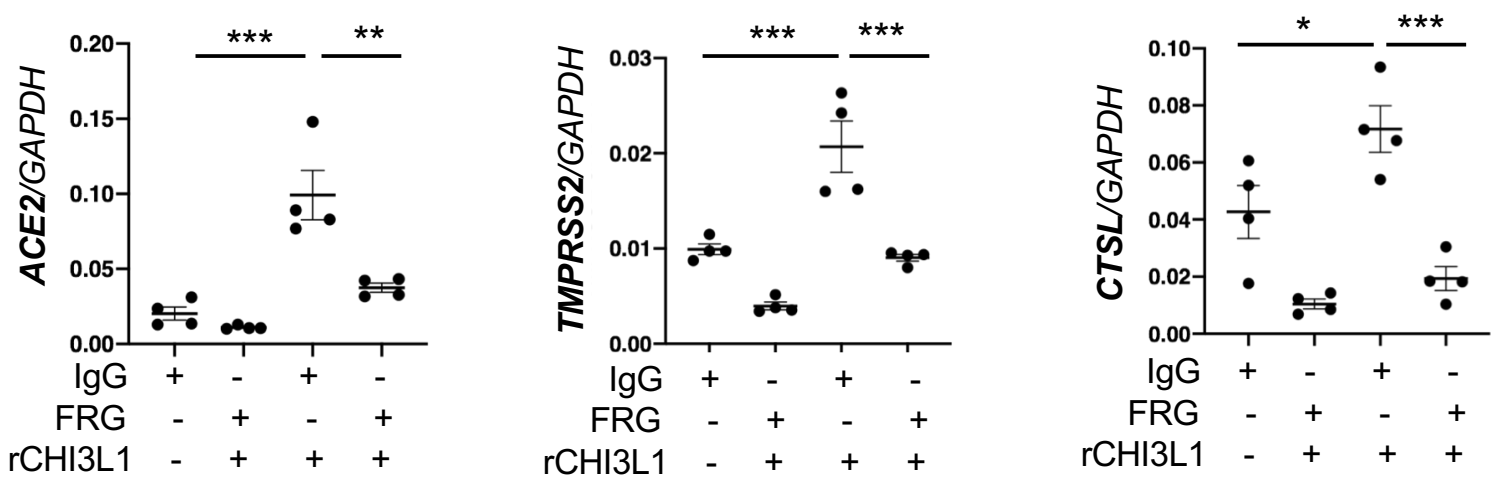

B
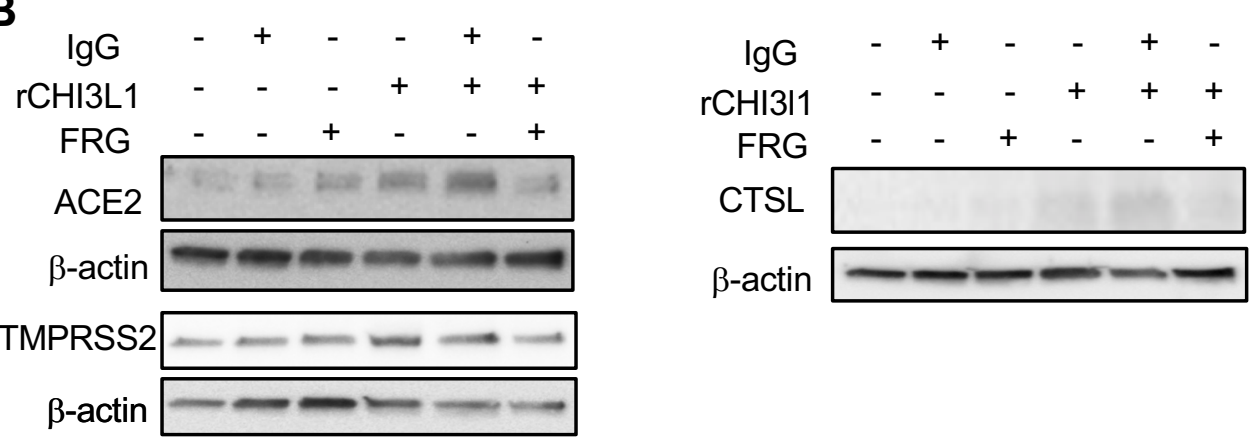

C
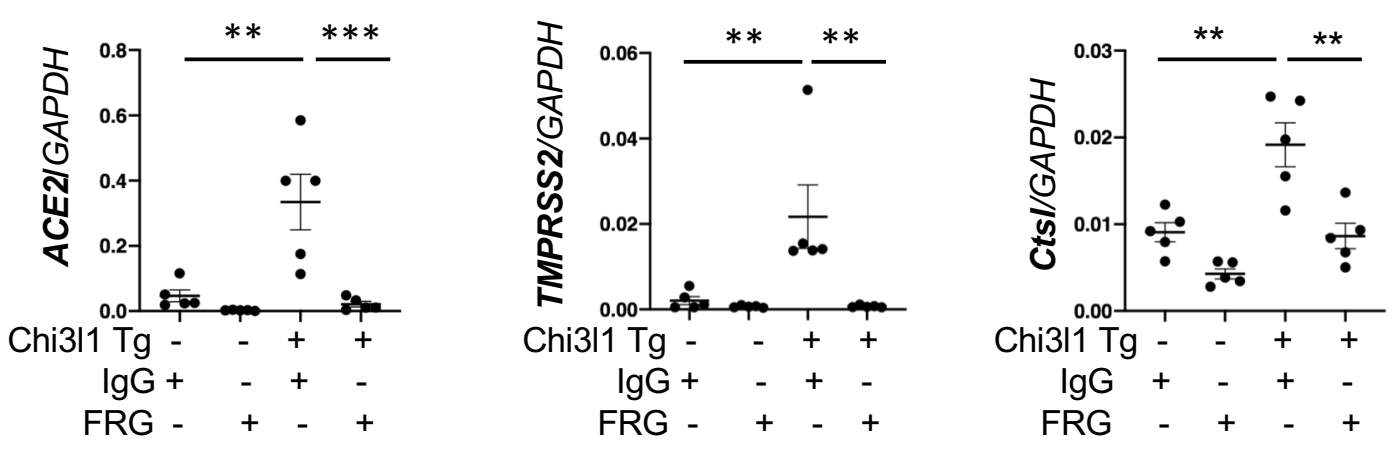

D
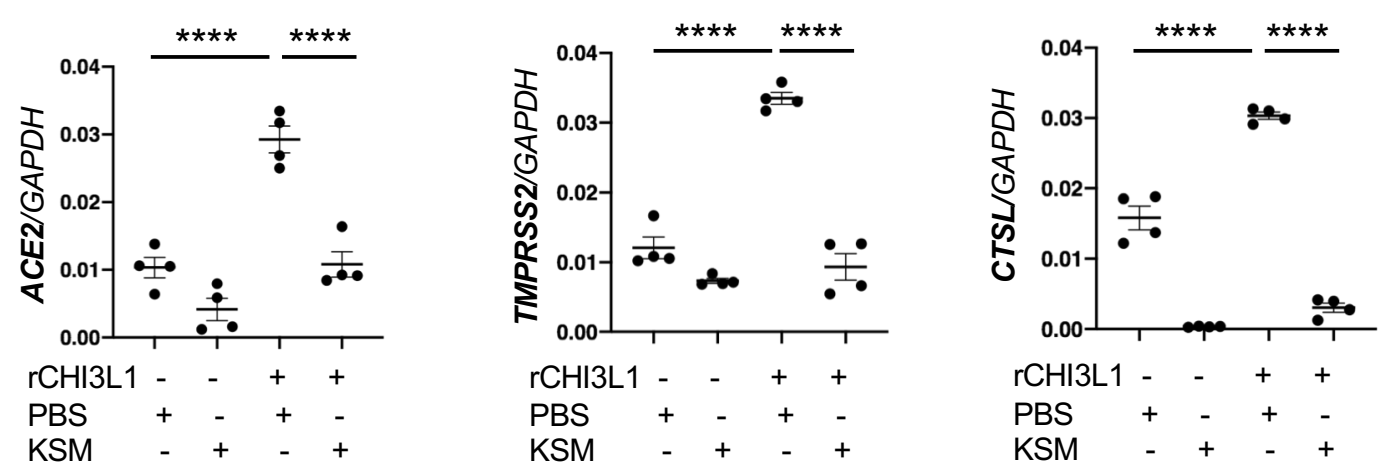


\section{Figure 4}

A

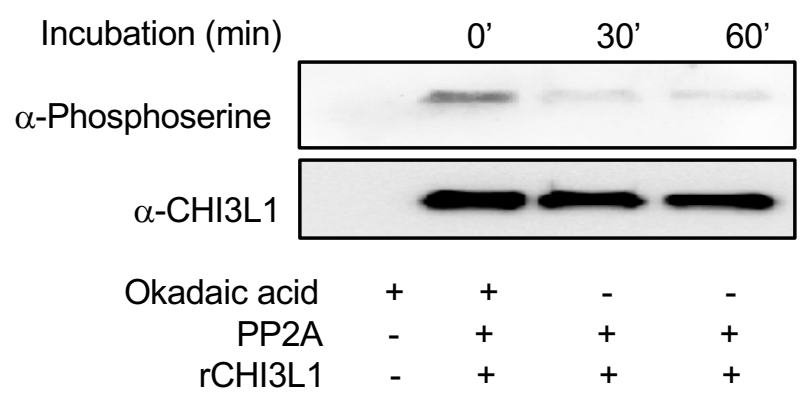

B

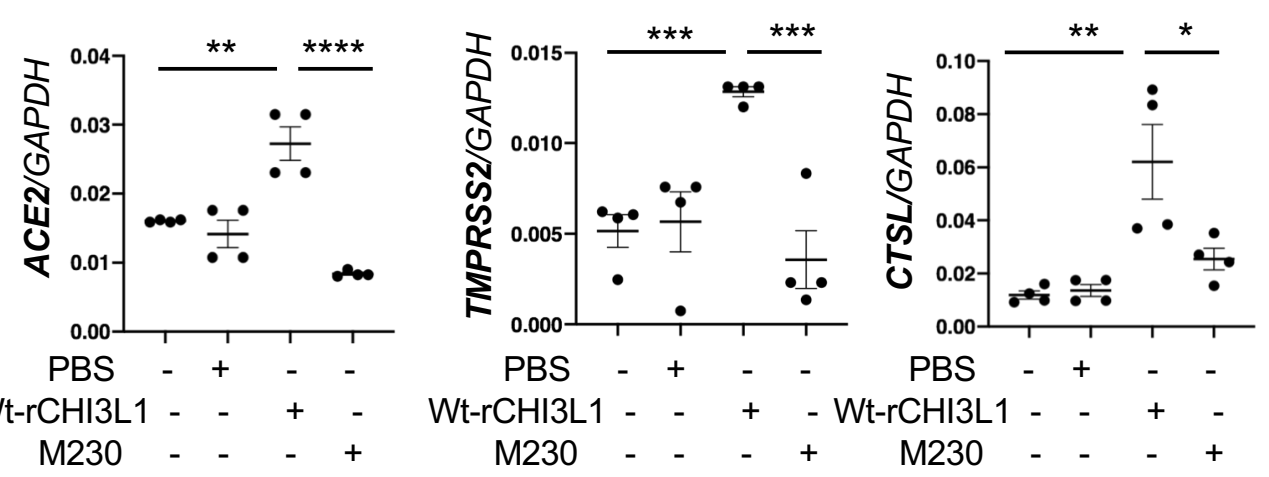

C
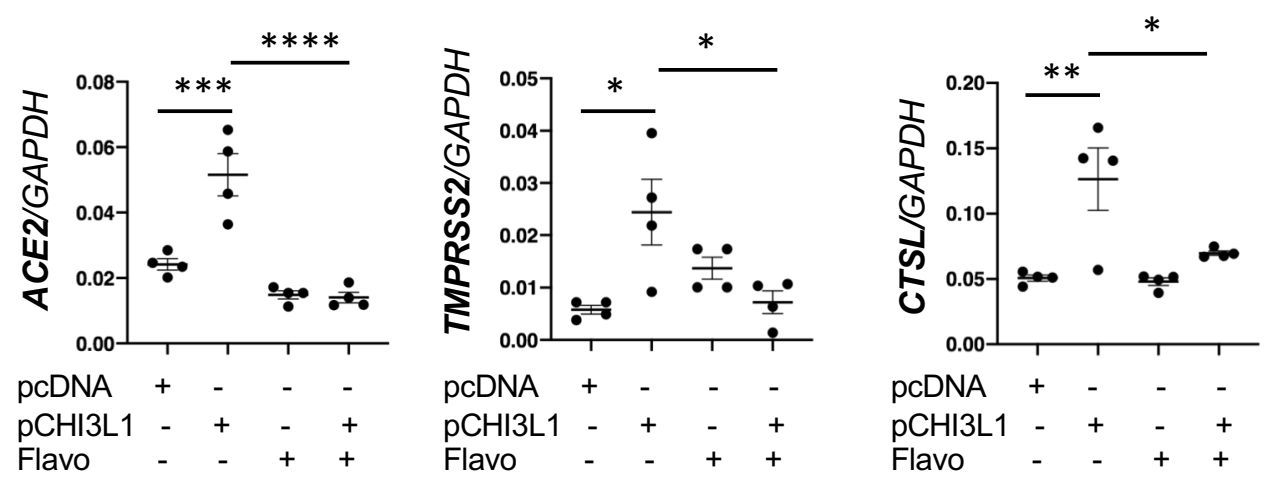

D
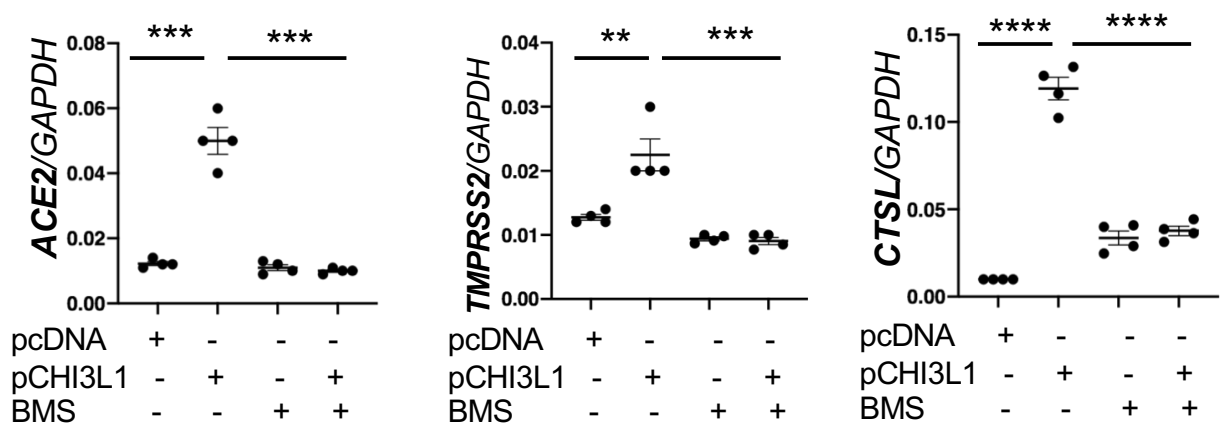


\section{Figure 5}

A
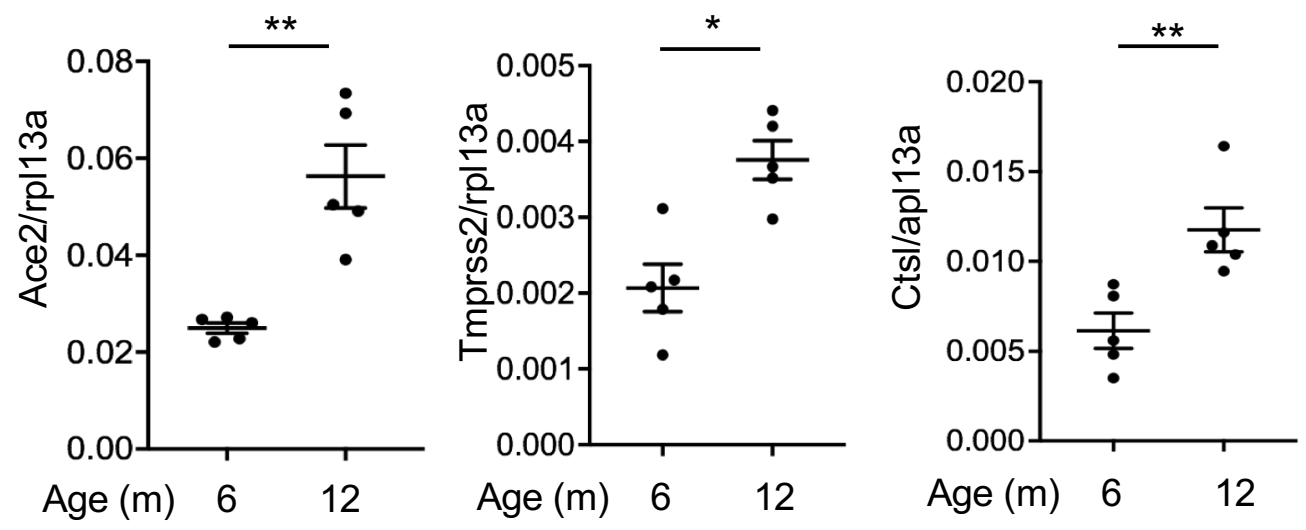

B
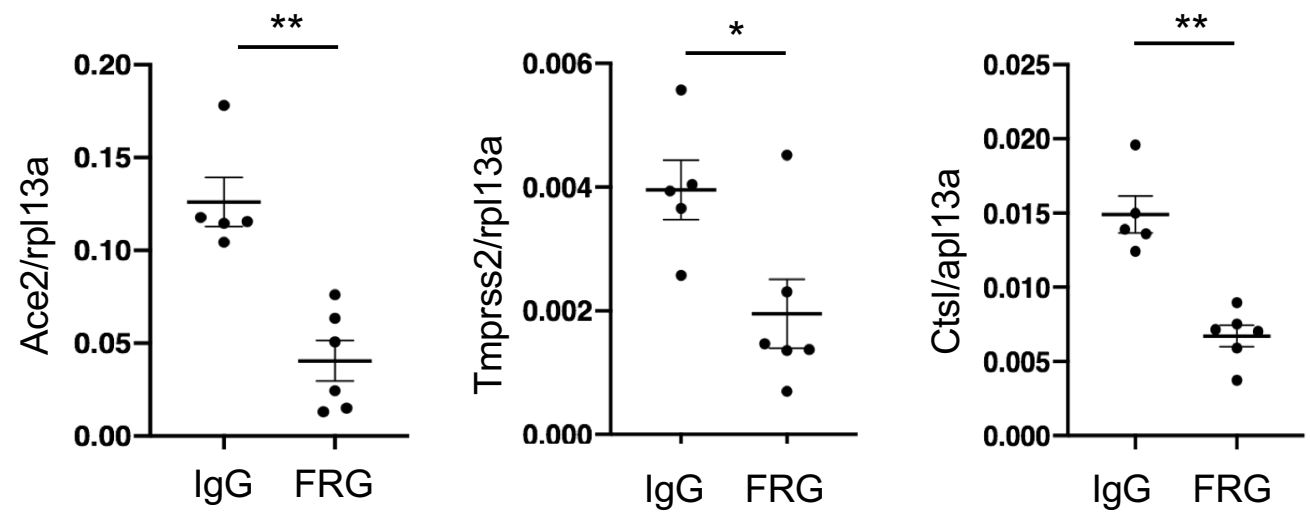


\section{Figure 6}

A

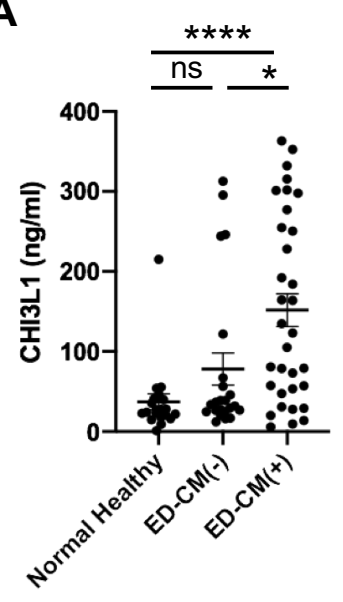

E

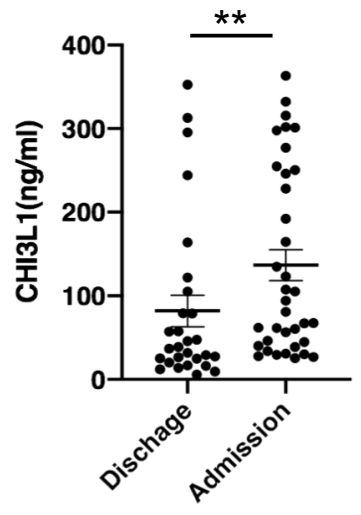

G
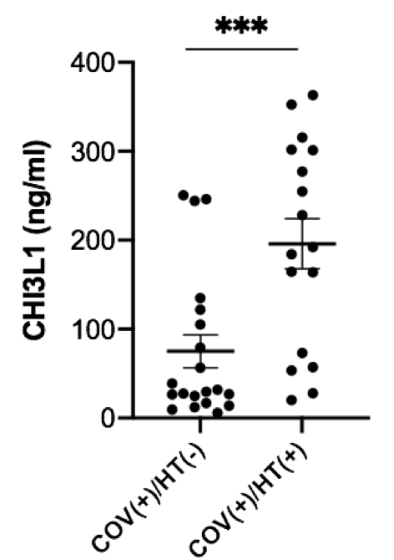

B

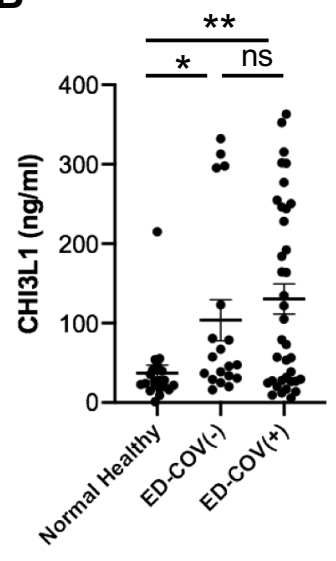

C

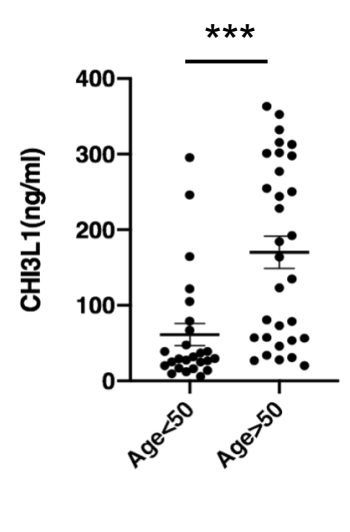

F

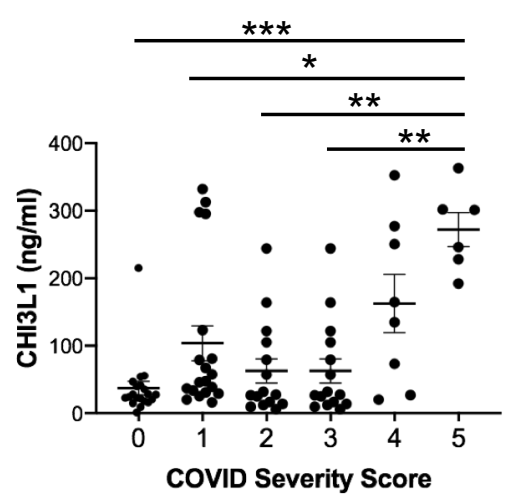

H

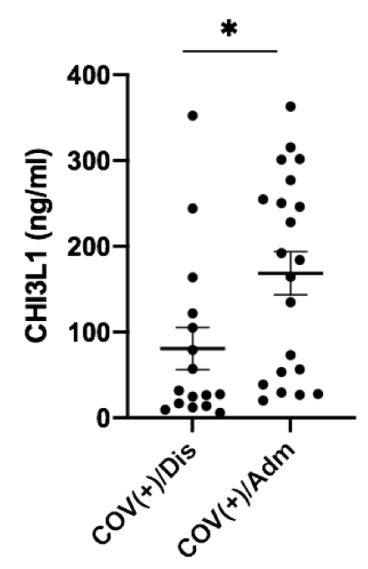

I

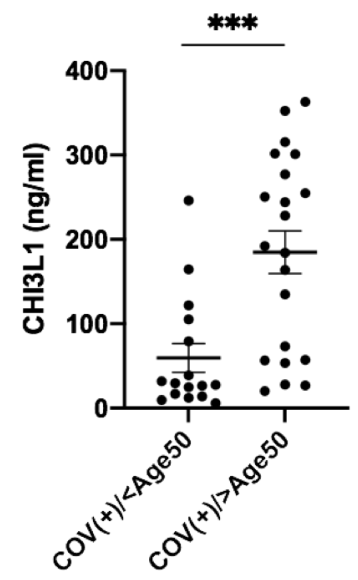

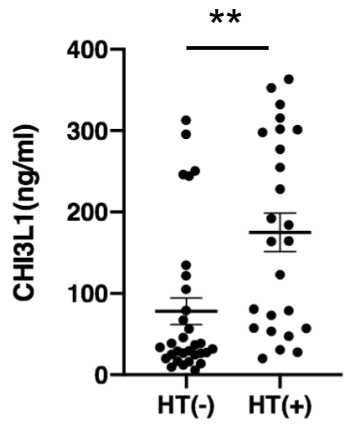

J

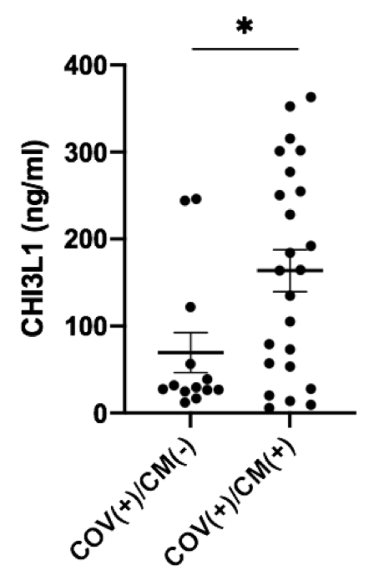

